\title{
Desmosomes and Intermediate Filaments: Their Consequences for Tissue Mechanics
}

\author{
Mechthild Hatzfeld, ${ }^{1}$ René Keil, ${ }^{1}$ and Thomas M. Magin ${ }^{2}$ \\ ${ }^{1}$ Institute of Molecular Medicine, Division of Pathobiochemistry, Martin-Luther-University Halle-Wittenberg, \\ 06114 Halle, Germany \\ ${ }^{2}$ Institute of Biology, Division of Cell and Developmental Biology and Saxonian Incubator for Clinical \\ Translation (SIKT), University of Leipzig, 04103 Leipzig, Germany \\ Correspondence: thomas.magin@uni-leipzig.de; mechthild.hatzfeld@medizin.uni-halle.de
}

\begin{abstract}
Adherens junctions (AJs) and desmosomes connect the actin and keratin filament networks of adjacent cells into a mechanical unit. Whereas AJs function in mechanosensing and in transducing mechanical forces between the plasma membrane and the actomyosin cytoskeleton, desmosomes and intermediate filaments (IFs) provide mechanical stability required to maintain tissue architecture and integrity when the tissues are exposed to mechanical stress. Desmosomes are essential for stable intercellular cohesion, whereas keratins determine cell mechanics but are not involved in generating tension. Here, we summarize the current knowledge of the role of IFs and desmosomes in tissue mechanics and discuss whether the desmosome-keratin scaffold might be actively involved in mechanosensing and in the conversion of chemical signals into mechanical strength.
\end{abstract}

$T^{1}$ he majority of tissues are constantly exposed to external forces, such as mechanical load, stretch, and shear stress, in addition to intrinsic forces generated by contractile elements inside tissues. Both extrinsic and intrinsic forces contribute to tissue morphogenesis, homeostasis, and regeneration and affect cell shape, proliferation, and migration (Evans et al. 2013). Sensing and transmitting forces depend to a large extent on tight interactions between cell adhesion complexes and the cytoskeleton. Mechanosensing and mechanotransduction can be defined as cellular processes that convert mechanical cues into intracellular signaling (Furuse et al. 2002; Huveneers and de Rooij 2013; Janmey et al. 2013). These processes are exemplified by epithelia that line organ and body surfaces to provide structural support and serve as barriers against diverse external stressors such as mechanical force, pathogens, toxins, and dehydration. Epithelia contain two types of intercellular adhesion complexes: adherens junctions (AJs) and desmosomes, connected to the actin and keratin cytoskeleton, respectively (Fletcher and Mullins 2010).

The detailed molecular mechanisms that underlie mechanotransduction are complex and only partially understood. Recent data indicate that mechanosensor proteins can undergo force-induced conformational changes that, in turn, induce changes in their activity or affinity for binding partners (Yonemura et al. 2010;

Editors: Carien M. Niessen and Alpha S. Yap

Additional Perspectives on Cell-Cell Junctions available at www.cshperspectives.org

Copyright (C) 2017 Cold Spring Harbor Laboratory Press; all rights reserved; doi: 10.1101/cshperspect.a029157

Cite this article as Cold Spring Harb Perspect Biol 2017;9:a029157 
M. Hatzfeld et al.

Huveneers and de Rooij 2013). This can finally lead to the activation of chemical signaling cascades. As discussed in Yap (2017), AJs function as mechanosensors (Huveneers and de Rooij 2013; Yao et al. 2014; Ladoux et al. 2015; Muhamed et al. 2016), whereas a role in force sensing has so far not been attributed to desmosomes. At the same time, desmosome-mediated intercellular adhesion is much stronger than AJmediated cohesion as shown by the epithelial sheet assay: Whereas depletion of the desmosomal plaque component plakophilin 1 (PKP1) in keratinocytes disrupts epithelial cohesion on application of mechanical stress, knockdown of the corresponding components from AJs, p120, or p0071/PKP4, has no immediate effect on intercellular cohesion (Fig. 1). Thus, this suggests that in tissues in which both junctions are present, AJs are important in mechanosensing, whereas desmosomes are crucial for providing mechanical stability under force.

Here, we will review the contribution of the desmosome-keratin complex to mechanical integrity of epithelial barriers, in particular of the epidermis, and discuss their potential function in sensing and transmission of forces. For the role of intercellular contacts and intermediate filaments (IFs) of the heart, the reader is referred to recent reviews (Meens et al. 2013; Patel and Green 2014).

\section{FUNCTION OF DESMOSOMES IN CONFERRING MECHANICAL STABILITY}

\section{Composition and Structure of Desmosomes}

Desmosomes are intercellular junctions essential for mediating strong intercellular cohesion (Garrod 2010; Green et al. 2010; Kowalczyk and Green 2013). They are composed of three protein families. The desmosomal cadherins, desmogleins (DSGs), and desmocollins (DSCs), are transmembrane proteins whose extracellular domains form the adhesive interface of the desmosome, whereas their cytoplasmic tails anchor the armadillo proteins, plakoglobin (PG/JUP), and plakophilins 1-3 (PKPs) to the desmosomal plaque. The armadillo proteins, in turn, bind to desmoplakin (DSP), a member of the plakin family of cytoskeleton-associated proteins. DSP links the desmosome to the keratin filament network, which is essential to provide tensile strength (Fig. 2). The importance of desmosomes for tissue integrity is highlighted by the severe skin and cardiac defects that arise in autoimmune and genetic diseases.
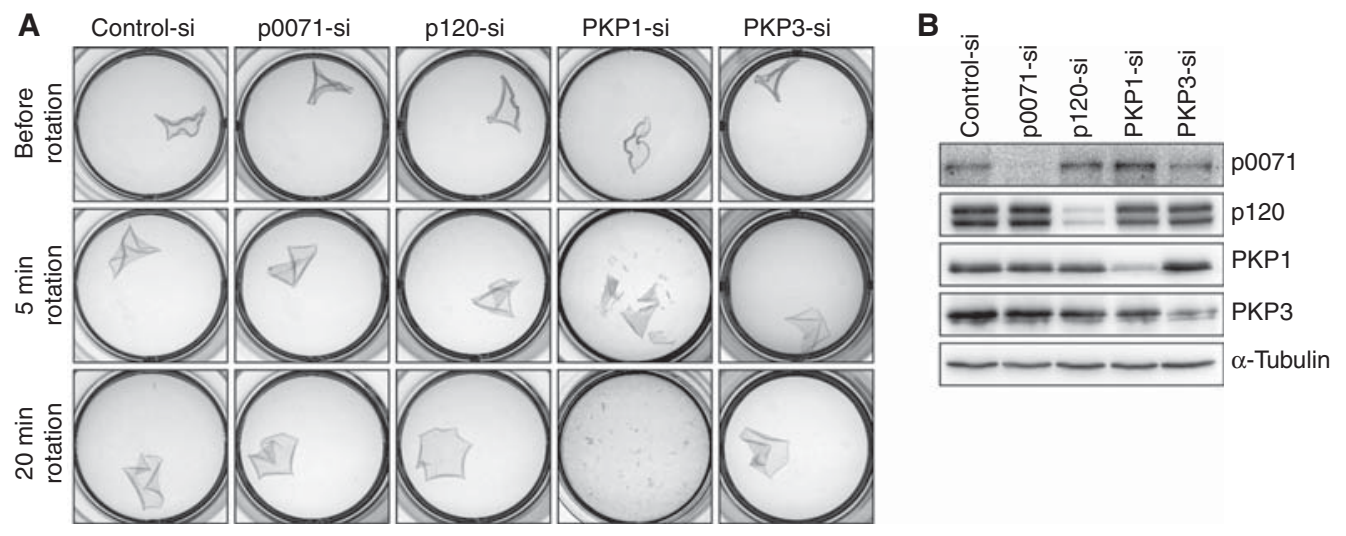

Figure 1. Dispase-based dissociation assay highlights the importance of desmosomes for intercellular cohesion. Only the knockdown of the desmosomal plaque protein plakophilin 1 (PKP1) severely disturbed intercellular cohesion of mouse keratinocytes grown for $24 \mathrm{~h}$ in a medium containing $1.2 \mathrm{mM} \mathrm{Ca}^{2+}$. The knockdown of the corresponding proteins from adherens junctions (AJs), p120, or p0071/PKP4 did not interfere with mechanical resistance of mouse keratinocytes $(A)$, although the respective protein amounts were considerably decreased as shown by western blot $(B)$. 


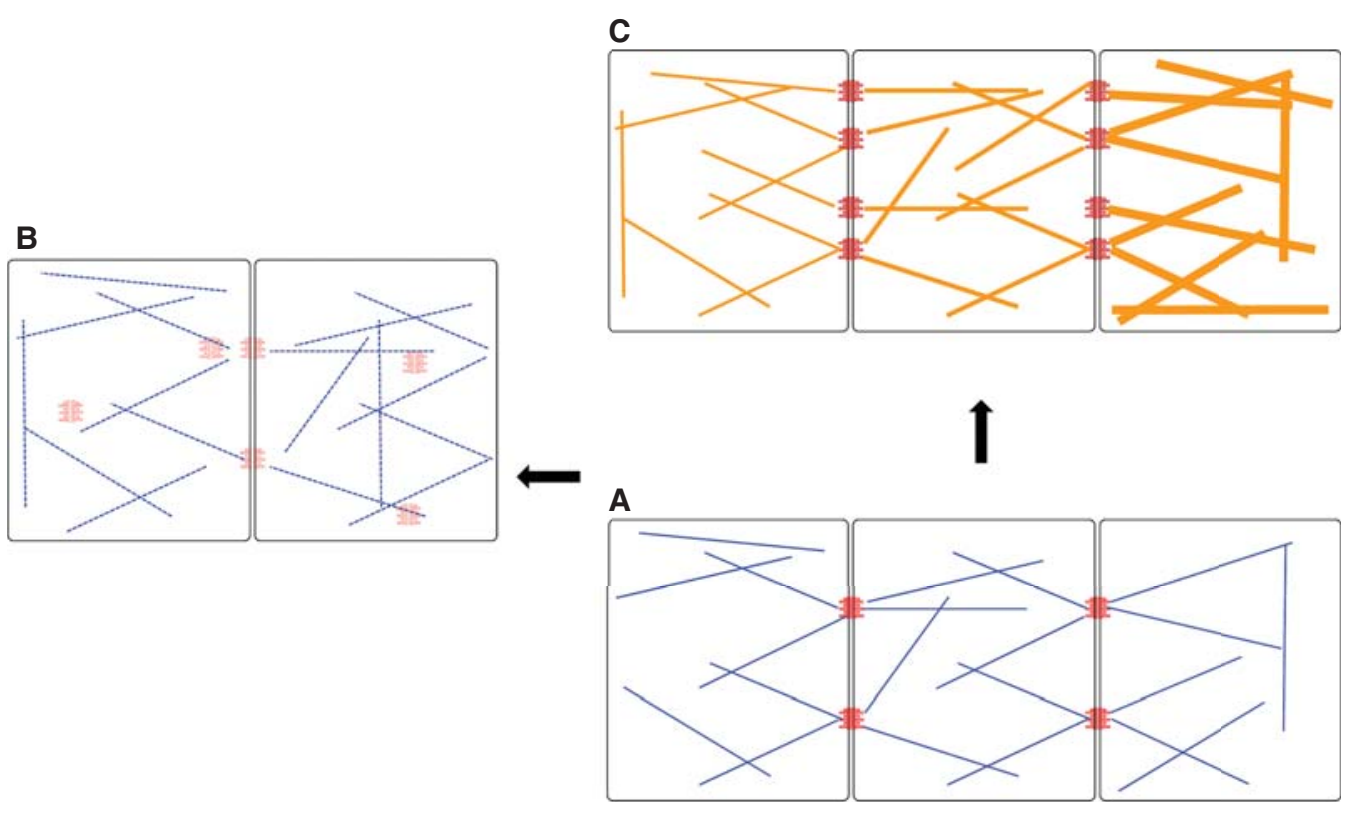

Figure 2. The desmosome-keratin complex as a micromechanical scaffold during epidermal differentiation. (A) Expression of keratins K5/14 and interaction with desmosomal protein isoforms forms stable cohesion among cells and protects basal keratinocytes against mechanical stress. Under conditions of tissue homeostasis, stable desmosome-keratin scaffolds prevail. (B) Cells react to wounding (activated keratinocytes) by modulating their micromechanical properties through altering adhesion and the cytoskeleton. Underlying mechanisms involve altered expression of isotype proteins and posttranslational modifications that can diminish adhesion and render cells more migratory. Expression of K6/16/17 coincides with dynamic desmosomes. (C) To withstand increased mechanical stress, for example, in upper strata of the epidermis, number and size of desmosomes are increased and keratin filaments become more abundant, bundled by associated proteins and possibly elevated interkeratin Cys crosslinks. Gray arrow in $(C)$ indicates tissue differentiation. Desmosomes are depicted to indicate stable adhesion (red), to demarcate dynamic, less adhesive (light red), and hyperadhesive complexes (dark red). Keratin filaments are drawn to indicate stable networks (straight blue lines), dynamic, less stable networks (dashed green lines) or to indicate highly resilient, bundled networks (orange thick lines). The above properties result from expression of distinct isotypes, relative abundance, and posttranslational modifications.

Desmosomal cadherins are divided into four DSGs and three DSCs. The DSG-DSC heterodimers represent the basic adhesive unit of desmosomes (Harrison et al. 2016). All DSGs form adhesive dimers with all DSC isoforms with affinities characteristic of each DSG-DSC pair. In contrast, homophilic DSG-DSG and DSC-DSC trans-interactions were suppressed by charged amino acids. In multilayered epithelia such as the epidermis, desmosomal cadherins reveal differentiation-dependent expression. DSG1, -4 , and DSC1 are expressed in flattened cells of the upper granular and cornified layers, whereas DSG2, -3, and DSC2, -3 occur primarily in the lower layers of the epidermis (Green and Gaudry 2000).

Despite their critical roles in maintaining epidermal adhesion and integrity, desmosomes are highly dynamic entities and undergo constant remodeling to allow for plasticity and cell migration within the epidermis during epidermal differentiation and regeneration (Green and Gaudry 2000; Garrod 2010; Kowalczyk and Green 2013). Desmosome adhesion can be regulated at several levels: Their composition, as well as size and number, vary among 
M. Hatzfeld et al.

tissues and among the individual layers of the epidermis, and are controlled at the transcriptional, posttranscriptional, and posttranslational levels.

Evidence from Mouse Models and Human Diseases

Gene ablation in mice has established the contribution of individual desmosomal proteins to mechanical stability and tissue integrity in vivo. These studies show (a) that many of the desmosomal proteins are required for organismal survival and (b) that isotypes of DSGs, DSCs, and PKPs have distinct functions in vivo. For example, phenotypes observed after ablation of the three DSC genes differ dramatically in their severity: Whereas a DSC2 knockout $(\mathrm{KO})$ did not result in any obvious phenotype (Rimpler 2014), ablation of DSC1 led to epidermal fragility with hyperproliferation and dermatitis, but mice were viable and fertile (Chidgey et al. 2001). In contrast, DSC3 ablation resulted in preimplantation lethality, suggesting a desmosome-independent role during early development (Den et al. 2006). Similarly, ablation of DSG isotypes revealed distinct functions in vivo: Whereas the DSG2 KO was embryonic lethal (Eshkind et al. 2002), DSG3 KO mice showed weakened desmosomal adhesion, leading to the separation of keratinocytes (Koch et al. 1997). The loss of DSG1 function has so far not been analyzed in mice as it requires deletion of all three DSG1 genes.

Desmosomal plaque proteins are equally important for intercellular cohesion and mechanical stability: PG/JUP KO embryos died as a result of severe heart defects with reduced and structurally altered desmosomes (Bierkamp et al. 1996; Ruiz and Birchmeier 1998). Although $\beta$-catenin, the homologue of $\mathrm{PG}$ in AJs, localized to desmosomes and could substitute for PG in cadherin clustering, it failed to recruit normal levels of PKP1 and DSP to the plaque (Bierkamp et al. 1999; Acehan et al. 2008). DSP KO embryos did not survive beyond embryonic day 6.5 and displayed severe defects in tissue architecture, shaping of the embryo, and in anchoring keratin filaments to desmo- somes (Gallicano et al. 1998). In an epidermisspecific DSP KO, intercellular separations were observed as expected (Vasioukhin et al. 2001). Surprisingly, desmosome number was unaltered although the lack of keratin association compromised their function. PKPs were previously considered as nonessential plaque proteins. However, PKP2 KO mice died around day 11.5 of embryonic development because of heart defects, indicating that at least one PKP is required for stable intercellular adhesion (Grossmann et al. 2004). In contrast, $\mathrm{PKP} 3^{-/-}$ mice were viable but developed hair abnormalities and increased inflammation of the skin, manifest in mice kept in a nonpathogen-free environment (Sklyarova et al. 2008). We have recently shown that $\mathrm{PKP} 1$ is essential for epidermal integrity in vivo. PKP1 KO mice died shortly after birth with defects in epidermal cohesion and barrier formation (Rietscher et al. 2016). Desmosomes were small and sparse in the skin, as well as in cultured keratinocytes derived from these mice, and cell separation occurred in the granular layers.

Additional support for the importance of desmosomal adhesion in tissue integrity comes from monogenetic human diseases. Ectodermal dysplasia-skin fragility syndrome (EDSFS, MIM604536), a genetic disease caused by PKP1 mutations (McGrath et al. 1997), is characterized by skin fragility with generalized superficial erosions and chronic inflammatory plaques and pruritus. Additional abnormalities include alopecia and nail dystrophy (McGrath et al. 1997; Sprecher et al. 2004; McGrath 2005; McGrath and Mellerio 2010). Desmosomes in the skin of patients were generally small with perturbed desmosome-keratin interactions. Severe dermatitis, multiple allergies and metabolic wasting (sinobronchial allergic mycosis, SAM) syndrome (MIM615508) is a recently described genodermatosis caused by homozygous mutations in DSG1 or DSP. Dermatologic manifestations comprise congenital erythroderma, striate palmoplantar keratoderma (SPPK), skin erosions, scaling, and hypotrichosis. Patients developed severe allergies, recurrent skin, and respiratory tract infections, indicating that loss of DSG1 interferes with skin barrier function (Sa- 
muelov et al. 2013; Has et al. 2015). More recently, a point mutation in the keratin-binding domain of DSP was identified as causing SAM syndrome (McAleer et al. 2015). Nonsense, as well as splice site mutations, have been observed in PG causing skin fragility, generalized epidermolysis, palmoplantar keratoderma, and woolly hair (Pigors et al. 2011; Li et al. 2012). Arrhythmogenic cardiomyopathy (AC) is a rare disease of the heart characterized by progressive myocardial dystrophy with fibro-fatty replacement. In the majority of cases, dominant mutations have been identified in desmosomal genes including DSP: ARVD8 (MIM607450); PKP2: ARVD9 (MIM609040); DSG2: ARVD10 (MIM610193); DSC2: ARVD11 (MIM610476); JUP: ARVD12 (MIM611528) (Al-Jassar et al. 2013; Cerrone and Delmar 2014; Calore et al. 2015; Pilichou et al. 2016).

Desmosomes can also be affected in acquired diseases, which comprise epidermal autoimmune disorders and infections (Stahley and Kowalczyk 2015). Pemphigus is a family of diseases characterized by circulating autoantibodies that target desmosomal proteins and compromise cell-cell adhesion (Amagai 2010; Jennings et al. 2011; Amagai and Stanley 2012). Pemphigus autoantibodies are directed against the extracellular domains of desmosomal cadherins and are sufficient to cause the loss of keratinocyte adhesion.

Taken together, these studies clearly indicate that desmosomes are essential for robust intercellular cohesion and tissue integrity under mechanical strain.

Why is Desmosomal Adhesion Stronger than AJ-Mediated Adhesion?

Isoform-Dependent Composition of Desmosomes Determines Adhesive Strength

Although the differential expression of desmosomal cadherins and PKPs has been known for a long time, experiments addressing their individual and distinct contributions to desmosomal adhesion have only recently emerged. Harrison et al. (2016) have systematically analyzed the structural basis of adhesive binding by DSGs
Desmosomes and Keratins in Tissue Mechanics

and DSCs. Using analytical ultracentrifugation and plasmon plasmon surface resonance resonance, these investigators determined $K_{D}$-values for DSG and DSC homodimers, as well as heterodimers. Whereas homodimers were very weak with $K_{D}$ values $>400 \mu \mathrm{M}$, heterodimeric pairs revealed $K_{D}$ s ranging from 3.6 to $43.9 \mu \mathrm{M}$, indicative of stronger adhesion than provided by E-cadherin (Harrison et al. 2016). These data correlate well with the role of AJs in mechanosensing and one for desmosomes in conferring stability. Interestingly, the strongest-binding pairs were Dsg1:Dsc1 and Dsg4:Dsc1, which are expressed in the outermost layers of the epidermis, whereas the basally expressed cadherins Dsg3:Dsc3 formed the weakest adhesive pair. This correlates with the force-protective function of the outer epidermal layers, although the basal layers must allow for remodeling and regeneration, which is facilitated by weaker adhesion. In agreement, preliminary experiments suggest an up-regulation of DSG1 on application of stretch to cultured keratinocytes (our own unpublished results).

Similarly, PKPs -1 and -3 contribute differentially to intercellular cohesion. A comparison of keratinocytes derived from the corresponding KO mice confirmed that the loss of PKP1 interfered with formation of a stable epithelial sheet, whereas adhesion was not compromised in PKP3 KO keratinocytes. Surprisingly, desmosomal PKP3 was not only much more dynamic compared with PKP1, but was able to destabilize PKP1-dependent desmosomes when overexpressed (Keil et al. 2016). Collectively, these data indicate that isoform expression has a considerable influence on desmosome stability and resistance to force and appears well suited to adapt desmosomes to mechanical stresses.

\section{Hyperadhesion is a Unique Feature of Desmosomes}

In contrast to AJs, desmosomes can occur in two functionally distinct adhesive states, which are distinguished on $\mathrm{Ca}^{2+}$-depletion. In normal tissues, desmosomes adopt a $\mathrm{Ca}^{2+}$-independent state, also referred to as hyperadhesion, which is crucial for stable intercellular cohesion 
M. Hatzfeld et al.

and resistance to mechanical strain (Garrod 2010; Thomason et al. 2010). In contrast, during regeneration and wound healing, desmosomes become $\mathrm{Ca}^{2+}$-dependent resulting in weaker intercellular cohesion, which allows for tissue remodeling (Wallis et al. 2000; Kimura et al. 2012). In cultured keratinocytes, desmosomes depend on extracellular $\mathrm{Ca}^{2+}$ after their formation but undergo a maturation process to become hyperadhesive. Although the mechanism controlling formation of $\mathrm{Ca}^{2+}$ - insensitive desmosomes is incompletely understood, one model predicts that a highly organized arrangement of the DSG and DSC extracellular domains is induced (Thomason et al. 2010), which correlates with a wider intercellular space and the presence of a midline observed in electron microscopic images, whereas $\mathrm{Ca}^{2+}$-dependent desmosomes appear to lack this midline (Garrod 2010).

Based on structural analyses of DSG2, Tariq et al. (2015) proposed that the flexibility of desmosomal cadherin ectodomains allows them to adopt a conformation that facilitates desmosome plasticity. The desmosomal plaque would contribute to plasticity by introducing spacings between desmosomal cadherins and preventing ectodomain cis-interactions. The distance between cadherins and the lack of cis-interactions facilitates conformational changes needed to adopt the ordered architecture in the $\mathrm{Ca}^{2+}$-independent state. Depletion of DSC2 prevented the acquisition of hyperadhesion in keratinocytes (Kurinna et al. 2014), although it is not known whether this is a unique feature of DSC2 or shared by all DSCs and DSGs. The fact that a DSC2 mouse KO did not reveal any phenotypic abnormalities (Rimpler 2014) suggests that hyperadhesion does not critically depend on the DSC2 isoform. In an attempt to characterize the combinatorial roles of DSCs and DSGs in desmosome assembly, micropatterned substrates were used to uncouple desmosome assembly from other cell contacts (Lowndes et al. 2014). In this assay, DSC2, but not DSG2, formed $\mathrm{Ca}^{2+}$-dependent homophilic bonds, indicating that DSC2 was required for desmosome assembly. In contrast, DSG2 formed $\mathrm{Ca}^{2+}$-independent heterophilic bonds with DSC2, suggesting a role of DSG2 in desmosome maturation and in the switch to $\mathrm{Ca}^{2+}$-independent adhesion (Lowndes et al. 2014).

Because an ordered intercellular zone requires an ordered plaque, desmosomal plaque proteins are also important in regulating desmosomal hyperadhesion. PKP1 overexpression induced $\mathrm{Ca}^{2+}$-independent hyperadhesive desmosomes. This prevented Pemphigus vulgaris (PV)-IgG-mediated desmosome disruption (Tucker et al. 2014), indicative of a very stable adhesive state. Moreover, PKP1 enhances desmosome size and number by laterally interacting with DSP in agreement with a postulated role of plaque proteins in mediating cadherin spacing (Kowalczyk et al. 1999; Hatzfeld et al. 2000; Bornslaeger et al. 2001; Hatzfeld 2007). Thus, the desmosomal cadherins, as well as the plaque protein PKP1, cooperate to provide strong adhesion and stability under mechanical strain.

What are the Upstream Signals that Modulate Desmosomal Adhesion?

\section{Cross Talk Desmosomes-AJ}

Epithelial junction assembly, maturation, and maintenance occur through sequential processes that are differentially regulated (Keil et al. 2016). Earlier work suggested a hierarchical process in which AJs form before desmosomes. However, increasing evidence indicates that newly formed contacts contain components of AJs and desmosomes, and sorting into distinct junctional complexes occurs on junction maturation in epithelial cells (Green et al. 2010; Keil et al. 2016).

PG was the first protein identified in desmosomes and AJs based on colocalization studies and its coimmunoprecipitation with E-cadherin (Cowin et al. 1986; McCrea et al. 1991). Gosavi et al. (2011) showed that PKP3, PG, and E-cadherin are present at the cell border when cells are grown in media with low concentrations of $\mathrm{Ca}^{2+}$ and suggested a model in which PG and E-cadherin recruit $\mathrm{PKP} 3$ to the cell border to initiate desmosome formation. A role of PKP3 in coordinating $\mathrm{AJ}$ and desmosome formation was further supported by the finding that PKP3 localization at the plasma membrane occurs together 
with E-cadherin and precedes other desmosomal proteins, including PKP1 and DSP (Keil et al.2016). At the molecular level, PKP3 forms a complex with the Rap1 GTPase, promoting its activation and facilitating desmosome assembly (Todorovic et al. 2014). Moreover, PKP3 was required for $\mathrm{AJ}$ maturation and sealing. These findings reveal PKP3 as a coordinator of desmosome assembly and AJ maturation through its association with Rap1 (Todorovic et al. 2014).

\section{Actin and Desmosomes}

Formation of AJs but not desmosomes coincides with an increase in the apparent stiffness of cell monolayers reflecting the generation of a tissue-level tension (Harris et al. 2014). Tension rapidly increases with a maximum at $150 \mathrm{~min}$, which correlates with the initiation of desmosome assembly. Although desmosomes are associated with IFs and according to current views are unable to generate tension, their assembly requires actin microfilaments (Pasdar and $\mathrm{Li}$ 1993). It is, therefore, possible that AJ-associated actomyosin-dependent force generation is an important signal for desmosome formation although direct experimental evidence remains to be adduced.

The AJ protein p120 plays an essential role in limiting actomyosin-dependent tension generated at AJ as shown by uncoupling p120's cadherin-stabilizing and RhoA-suppressing activities. Removing p120's Rho-suppressing activity lead to excessive actomyosin contractility along the vertical axis of cells and disrupted the integrity of the apical surface, irrespective of Ecadherin stability (Yu et al. 2016). Interestingly, p120 has been described to associate with desmosomes during their formation in a $\mathrm{Ca}^{2+}$. shift experiment (Kanno et al. 2008).

Desmosomes can also influence actin organization: Loss of any of the PKPs from human or mouse keratinocytes results in changes in cortical actin organization (Godsel et al. 2010; Keil et al. 2016). However, it is not clear whether PKPs regulate RhoA activity and stress fiber formation directly or indirectly, by influencing the localization or activity of a Rho GEF or a Rho GAP (Godsel et al. 2010).

\section{Mechanosensitive Signaling Pathways in the Control of Desmosomes}

So far, little is known about how desmosome gene transcription and isotype expression are controlled and how mechanical stimuli direct these processes. Several recent studies have addressed the question how external mechanical forces are transmitted into chemical signals. To induce changes in the cell's gene expression program, signaling molecules regulated by external forces must be translocated from the cytoplasm into the nucleus and nucleocytoplasmic shuttling has been suggested as a common theme in mechanotransduction (Sharili and Connelly 2014). The SRF (serum-response factor) and YAP (Yes-associated protein)/TAZ (transcriptional coactivator with PDZ-binding motif) pathways are known mediators of this process in multiple cell types, including keratinocytes.

SRF transcriptional activity is regulated by actin and RhoA and its cofactors MRTF (myocardin-related transcription factor) $-\mathrm{A}$ and $-\mathrm{B}$. Monomeric actin sequesters MRTFs, which are released on actin polymerization and accumulate in the nucleus where they interact with SRF to stimulate target gene expression. Intercellular tension can increase actin polymerization at $\mathrm{AJs}$ and drive MRTF-A translocation into the nucleus (Gomez et al. 2010). SRF and MRTFs coactivate immediate early genes, such as JunB, and adhesion-related genes, including vinculin. Mice with a keratinocyte-specific SRF-KO revealed severe intercellular gaps between keratinocytes as the most striking pathophysiology (Koegel et al. 2009). The number of desmosomes was significantly lower in mutant compared with control mouse skin, whereas the size of individual desmosomes was unaltered. However, a direct regulation of desmosomal genes was not supported by transcription profiles of SRF KO skin samples compared with control skin (Koegel et al. 2009). In contrast, loss of MRTF-A reduced the levels of DSG1 messenger RNA (mRNA) in keratinocytes, suggesting that DSG1 is directly regulated by the SRF/MRTF-A complex (Dubash et al. 2013). Another experiment showed that MRTF-A and SRF were 
M. Hatzfeld et al.

recruited to cis-regulatory elements of the PKP2 gene to regulate its expression (Leitner et al. 2011). Taken together, these data suggest that RhoA/MRTF-A signaling in keratinocytes affects the expression of desmosomal proteins directly and indirectly although the regulation via SRF/MRTF-A in response to mechanical strain has not been directly shown.

The transcription factor AP-1 mediates gene expression in response to a variety of extracellular stimuli and is activated by SRF/MRTF signaling (Wang et al. 2015). Microarray analysis performed on mechanical stretched and normal human skin revealed an up-regulation of AP-1 in mechanically stretched skin (Yang et al. 2011). Other stimuli of AP-1 include growth factor signaling via mitogen-activated protein (MAP) kinases, which are also activated in response to mechanical stress (Kippenberger et al. 2000). AP-1 acts as a homodimeric or heterodimeric transcription factor composed of members of the Fos (c-Fos, FosB, Fra-1, and Fra-2) and Jun (c-Jun, JunB, and JunD) families. Jun is regarded as a positive regulator of keratinocyte proliferation/differentiation during development and in skin cancer through its direct transcriptional effect on epidermal growth factor receptor (EGFR) expression. In contrast, JunB can antagonize proliferation of keratinocytes. AP-1 target genes include keratins (Yates and Rayner 2002).

The Hippo signaling pathway is another regulator of mechanotransduction. It regulates organ size, tissue regeneration, and stem cell renewal (Zhang et al. 2011; Barry and Camargo 2013). Recently, mechanical signals were found to be transduced by the two mediators of the Hippo pathway, the transcriptional coactivators YAP and TAZ (Dupont et al. 2011). In the skin, YAP is required for epidermal barrier formation, hair follicle development, and maintenance of the epidermal stem cell compartment (Zhang et al. 2011; Barry and Camargo 2013; O’Neill 2015). Overexpression of YAP in transgenic mice promotes squamous cell carcinoma formation (Chan et al. 2011; Jia et al. 2016), whereas its knockdown inhibits cutaneous wound healing (Lee et al. 2014), suggesting a central role in regulating proliferation. YAP and TAZ also respond to the rigidity of the extracellular matrix, cell geometry, cell density, cell polarity, and the status of the actin cytoskeleton. Sensing of substrate stiffness by YAP/TAZ depends on the tension of the actin cytoskeleton (Zhang et al. 2011; Elbediwy et al. 2016). The AJ protein $\alpha$-catenin limits YAP activity by modulating its interaction with 14-3-3 (Kanai et al. 2000; Schlegelmilch et al. 2011; Sambandam et al. 2015). YAP/TAZ mediate their function in controlling gene expression through interaction with TEAD transcription factors, which drive the expression of proliferative genes (Zhang et al. 2011). Although YAP activation accelerates proliferation and suppresses differentiation of mouse keratinocytes, which correlates with altered desmosome number, size, and composition, a role of YAP/TAZ/TEAD in the transcriptional regulation of desmosomal genes has not been directly addressed. However, a large scale ChIP-seq analysis of Tead4 target genes in ECC1 endometrial cells identified DSCs 1-3, DSG1, DSP, PG, and PKPs -1 and -2 as putative Tead 4 target genes (Liu et al. 2016).

\section{ROLE OF IFs IN MECHANICAL STABILITY}

\section{Composition, Assembly, and Organization of Keratin Filaments}

IFs can be assembled from a superfamily of approximately 70 proteins that form cell-typespecific cyto- and nucleoskeletal arrays in the majority of multicellular animal species. Based on sequence homology and expression, IFs are grouped into six classes, all of which except lamins form predominantly cytoplasmic assemblies (Schweizer et al. 2006; Hobbs et al. 2016). Here, we focus on epithelial keratins to examine their contribution to the mechanical resilience of epithelia in conjunction with desmosomes, although desmin and vimentin also interact with desmosomes in cardiac tissue, meningiomal, and arachnoidal cells in which they fulfill analogous functions (Kartenbeck et al. 1983, 1984).

Keratin assembly begins with heterodimerization of type I and II keratin molecules, followed by formation of antiparallel tetramers. The lateral association of four tetramers gener- 
ates so-called unit-length filaments (ULFs), which longitudinally coalesce into mature filaments with a propensity to bundle and organize into three-dimensional (3D) networks (Herrmann et al. 2009; Koster et al. 2015; Herrmann and Aebi, 2016). Keratins show extensive sequence diversity, a feature that discriminates them from actins and tubulins (Schweizer et al. 2006; Fletcher and Mullins 2010). This sequence diversity is responsible for their relative affinities to each other and to associated proteins, and enables isotype-specific posttranslational modifications (Hatzfeld and Franke 1985; Hofmann and Franke 1997; Snider and Omary 2014). In humans and the mouse, 28 type I keratins (KtyI) and 26 type II keratins (KtyII) genes are predominantly expressed as pair-specific combinations of types I and II keratin proteins, respectively, in epithelial cells and tissues. The major impact of keratins on cell integrity and adhesion is most obvious in the epidermis, in addition to embryonic epithelia (Simpson et al. 2011; Bouameur and Magin 2017). The basal compartment expresses the keratin pair KRT5/KRT14, organized in loose bundles that extend from hemidesmosomes and desmosomes. On terminal differentiation, these keratinocytes disconnect from the ECM accompanied by replacement of KRT5/KRT14 with KRT1/KRT10. Depending on regional differences in the epidermis, additional keratins become expressed. At sites of high mechanical strain, such as palms and soles, the keratins KRT1/KRT10 are supplemented by keratins KRT2e and KRT9 (Moll et al. 2008). Analogous to desmosomes, keratin concentration increases from $40 \mu \mathrm{g} / \mathrm{ml}$ in basal keratinocytes to probably twice as much in terminally differentiated keratinocytes (Sun and Green 1978; Feng et al. 2013). The above keratin expression pattern varies, for example, during epidermal injury, which triggers the rapid induction of KRT6, -16, and -17 at the wound edge at the expense of KRT1/ 10 , accompanied by fewer and less adhesive desmosomes (Garrod and Chidgey 2008; Simpson et al. 2011). KRT6, KRT16, and KRT17 are also expressed in hair follicles and the nails (Moll et al. 2008). Epidermal stem cells are located in protected niches, such as the bulge of the hair follicle, and are characterized by the expression of KRT15 (Lyle et al. 1998; Watt 1998; Goldstein and Horsley 2012). The vibrissae bulge harbors two types of slow cycling stem cells, characterized by the expression of KRT5/15/17/19 and KRT5/17, respectively, which display loose keratin bundles in the former and tight bundles in the latter configurations (Larouche et al. 2008). Notably, in both subpopulations lacking KRT14, keratin network organization is different. The complexity of keratin expression suggests that keratins contribute to an intracellular epithelial niche, analogous to a stem cell niche (Tumbar et al. 2004), that endows distinct epithelial cells with unique micromechanical properties through formation of specifically tailored keratin-desmosome networks (Fig. 2).

\section{Human Disease and Mouse Models}

The importance of keratins for providing mechanical stress resilience in the epidermis is best documented by blistering and hyperkeratotic skin disorders exemplified by Epidermolysis bullosa simplex (EBS; OMIM \#131900), caused by mutations in KRT5 and KRT14 (Szeverenyi et al. 2008). EBS is characterized by cytoplasmic keratin aggregates, cytolysis of basal keratinocytes, and bullous lesions following mild trauma to the skin. Although it is recognized that the pathomechanisms contributing to EBS and additional keratinopathies are more complex than originally considered (Coulombe and Lee 2012; Roth et al. 2012; Bohnekamp et al. 2015; Hobbs et al. 2016; Kumar et al. 2016), it is evident that loss of an intact keratin cytoskeleton renders keratinocytes fragile on mild physical stress, shown by KRT5 and KRT14 KO mice (Lloyd et al. 1995; Peters et al. 2001). Of note, even mutations causing severe disease do not prevent formation of long keratin intermediate filaments (KIFs) in vitro (Herrmann et al. 2002), suggesting that mutations and physical stress act at the level of keratin bundling, network organization, dynamics, or by affecting association with other proteins. Indeed, the most frequent KRT14 Arg125 mutation compromises desmosome adhesion (Russell et al. 2004; Homberg et al. 2015). 
M. Hatzfeld et al.

Deletion and/or mutation of other keratin isotypes expressed in different epidermal compartments, either in the mouse or in humans, did not cause cytolysis and skin blistering to the same extent as KRT5 and KRT14, but was typified by altered cell and tissue growth, barrier, and immune defects (Reichelt et al. 2001; McGowan et al. 2002; Lessard and Coulombe 2012; Roth et al. 2012; Fischer et al. 2014, 2016; Fu et al. 2014; Kumar et al. 2016; Bouameur and Magin 2017). Transgenic expression of a bundling-competent KRT5/KRT8 chimaera partially rescued $\mathrm{KRT} 5^{-/-}$mice, whereas expression of bundling-deficient KRT8 did not, providing strong evidence that, in addition to keratin abundancy, isotype-specific properties and keratin network organization are crucial contributors to keratin-mediated stress resilience (Alvarado and Coulombe 2014).

The known redundancy of keratin expression in part explains lack of similarly severe defects in other epithelial compartments and complicates the analysis of isotype-specific functions (Reichelt et al. 2001; McGowan et al. 2002; Lessard and Coulombe 2012; Roth et al. 2012). To overcome the latter, mice lacking the entire KtyI and KtyII genes in their epidermis were generated, in addition to mice lacking both KRT1 and KRT10. Such mice developed a fully stratified epidermis but died perinatally because of extensive epidermal damage (Wallace et al. 2012; Bar et al. 2014; Kumar et al. 2015). Most importantly, these mice showed diminished intercellular adhesion and significantly smaller desmosomes. This was accompanied by accumulation of desmosomal proteins in the cytoplasm, highlighting that in vivo interaction with keratins was required for the maintenance of functionally intact desmosomes.

Interdependence of Keratins and

Desmosomes

Desmosomes have been recognized early on as important sites for KIF formation and organization in vivo (Jackson et al. 1980; Bologna et al. 1986; Schwarz et al. 2015), and genetic deletion of DSP can cause extensive reorganization or collapse of KIF, depending on the cell type
(Gallicano et al. 1998; Vasioukhin et al. 2001; Sumigray and Lechler 2012). Moreover, DSP and DSG1 mutations can give rise to SPPK (OMIM \#612908, \#148700, respectively), a hyperkeratotic skin condition with fewer or smaller desmosomes in the suprabasal epidermis and perinuclear accumulation of KIF in DSP-associated SPPK (Wan et al. 2004). Conversely, deletion of keratins reduced DSP deposition at the plasma membrane (Loranger et al. 2006; Vijayaraj et al. 2009). Distinct steps during desmosome assembly also require a transient but stable interaction between DSP and KIF in the cytoplasm (Godsel et al. 2005; Hobbs and Green 2012; Albrecht et al. 2015).

Keratins interact with the plectin and DSP carboxy termini through segments of their rod domain (Meng et al. 1997; Fontao et al. 2003; Bouameur et al. 2014). Association with keratins is regulated by serine phosphorylation and arginine methylation of the DSP tail, involving a coordinated activity of glycogen synthase kinase 3 (GSK3) and protein arginine methyltransferase 1 (PRMT1). Inhibition of GSK3 or PRMT1 delayed desmosome assembly and enhanced DSP-KIF interactions in the cytoplasm (Albrecht et al. 2015). In the absence of keratins, using keratinocytes from keratin-deficient mice (Vijayaraj et al. 2009), DSP phosphorylation was elevated and desmosomes were endocytosed at accelerated rates. Such desmosomes were unable to render epithelial sheets stable on rotational stress (Kroger et al. 2013). Reexpression of KRT5 and KRT14 reconstituted properly formed desmosomes and shear-resistant intercellular adhesion. Preliminary evidence indicates that sequestration of protein kinase $\mathrm{C}-\alpha(\mathrm{PKC} \alpha)$ by the scaffold protein Rack1 and KRT5/14 contribute to the stabilization of desmosomes (Kroger et al. 2013), whereas PKP3 may recruit $\mathrm{PKC} \alpha$ to abrogate hyperadhesion (Keil et al. 2016). In agreement, loss of PKC $\alpha$ in mice delays reepithelialization following wounding and is accompanied by maintenance of hyperadhesive desmosomes (Thomason et al. 2012).

Reepithelialization requires not only altered adhesion of keratinocytes at the wound edge (Shaw and Martin 2009) but also diminished 
contacts of keratins to desmosomal proteins, along with elevated expression of KRT6/16/17 and a decrease in KRT1/10 (Patel et al. 2006). In agreement, cells expressing KRT6 or KRT17 show elevated, PKC $\alpha$-mediated desmosome disassembly and subsequent destabilization of epithelial sheets. In contrast, KRT5 or KR14 supported stable desmosomes, suggesting that expression of "wound healing" keratins weakens intercellular adhesion. Further studies suggest that the type II keratin KRT5 is a major determinant of desmosome stability (Loschke et al. 2016). In addition to PKC $\alpha$, p38 MAP kinase (MAPK) signaling downstream from the serine protease inhibitor SPINT1 participates in the interaction of keratins and desmosomal proteins (Kawaguchi et al. 2015).

Thus, available data provide strong evidence for an interdependence of keratins and DSP regulated by posttranslational modifications. The casein kinase I (CK-1 $\alpha)$ scaffold protein FAM83H regulates keratin networks by recruiting CK- $1 \alpha$ directly to keratins (Kuga et al. 2013). It may be additionally involved in membrane localization of desmosomal proteins and in regulating desmosome-keratin interactions (Kuga et al. 2016). Whether FAM83H activity toward keratins or desmosomal proteins is coordinated with force-dependent conformational changes in desmosomal proteins remains currently unknown. In Xenopus mesendoderm cells, increased tension at P-cadherin-containing junctions recruits PG/JUP to these sites. In turn, PG/JUP recruits KIF to these junctions to reorganize and reinforce the keratin cytoskeleton. Through this sequence of events, local forces from neighboring cells mediate keratin reorganization required for coordinated cell behavior (Weber et al. 2012).

Keratins as Main Determinants for the Mechanical Integrity of Keratinocytes and Tissues

The mechanical properties of epithelial cells largely depend on actin filaments, microtubules, and KIF (Fletcher and Mullins 2010; Koster et al. 2015). Although the contribution of actin filaments and microtubules to these properties is well accepted, the contribution of keratins to the resilience of epithelia against various types of deformation remained unknown. Unlike other cytoskeletal elements, IF networks are less rigid at low shear strain but harden at high strains and resist breakage, indicating that they are crucial for the maintenance of tissue integrity (Janmey et al. 1991, 2013). Using atomic force microscopy (AFM)-based single-cell compression to examine resistance against external pressure and global rupturing forces, keratinocytes were 670 times stiffer than most other cell types. Selective disruption of actin filaments and microtubules did not significantly alter keratinocyte mechanics (Lulevich et al. 2010). However, application of AFM to keratin-deficient individual keratinocytes revealed a significant softening of keratin-deficient cells (Ramms et al. 2013). Magnetic tweezer experiments additionally showed a major contribution of keratins to viscoelastic cell properties. Similar conclusions were reached using a microfluidic optical stretcher (Seltmann et al. 2013). To relate these findings to functional consequences, invasion and 3D growth assays were performed with normal and keratin-deficient keratinocytes, revealing higher invasiveness in the latter. However, this came at the price of increased disruption of cells during invasion, suggesting that certain levels of keratins or other IF proteins are required to sustain the invasive process (Cheung et al. 2013; Seltmann et al. 2013).

Beyond single cells, very little is known about the contribution of keratin architecture to tissue mechanics. A recent AFM-based study, using the human hair follicle as a model system, showed stiffening of the soft keratinocyte matrix at the base of the hair follicle $\sim 360$-fold, from $30 \mathrm{kPa}$ to $11 \mathrm{MPa}$ along the first millimeter of the follicle. This stiffening coincided with an increased thickness of keratin macrofibrils and their orientation. The continued stiffening likely is because of increasing network orientation, compaction, and mechanical reinforcement of the keratin macrofibrils by disulfide cross-links. This study links changes in the architecture and molecular structure of keratin macrofibrils to the local mechanical behavior at a tissue scale level (Bornschlogl et al. 2016). 
M. Hatzfeld et al.

Impact of Mechanical Stretch on the Desmosome-Keratin Complex

Exposure of keratinocytes to stretch results in rapid and transient induction of MAPK ERK1/2 and SAP kinases (Kippenberger et al. 2000; Yano et al. 2004), accompanied by altered keratin expression, increased keratin phosphorylation and reorganization of keratin networks (Yano et al. 2004; Snider and Omary 2014). At least in keratinocytes, mechanical stretching acts via induction of calcium influx, EGFR phosphorylation, and ERK1/2 activation (Yano et al. 2004). In this setting, the established role of DSG1 in EGFR signaling has not yet been examined, thus, it remains unknown whether keratin reorganization is mediated by desmosomes or affects them (Harmon et al. 2013). On mechanical stretch, keratinocytes expressing the disease mutation KRT10 Arg156His show stronger activation of p38 MAPK compared with control transfectants, which ultimately might drive hyperproliferation typical of the corresponding keratinopathy (Obarzanek-Fojt et al. 2011). In lung epithelial cells, shear stress, but not stretch, caused hyperphosphorylation and disassembly of KRT8 and KRT18-containing IF, regulated by PKC- $\delta$ (Ridge et al. 2005). Blocking the shear stress-mediated keratin hyperphosphorylation and reorganization decreased cell viability and increased apoptosis. Notably, shear stress induced bundling of KIF into thick fibrils. In this study, shear stress-mediated phosphorylation of KRT18 at Ser33 was a prerequisite for keratin network reorganization to alter cells' mechanical properties and sustain their integrity (Flitney et al. 2009; Sivaramakrishnan et al. 2009).

To understand how phosphorylation affects keratin reorganization, select phosphomutants of KRT8 and KRT18 were characterized for their network mechanical properties using rheology and electron microscopy. Phosphokeratin-containing networks showed reduced intraconnectivity and resulted in mechanically weaker and more deformable networks in vitro. This appeared to result from the formation of shorter mutant filaments (Deek et al. 2016). In cultured cells, hyperphosphorylation alters the stretch response of keratins, affecting predominantly the peripheral keratin network (Fois et al. 2013). A set of studies has investigated biophysical and physiological consequences of hyperphosphorylation on normal and mutant keratins. The bioactive lipid sphingosylphosphorylcholine (SPC) activates JNK and Erk kinases, mediating keratin reorganization through phosphorylation of KRT8 at Ser431 and KRT18 at Ser52 in pancreatic tumor cells. The resulting perinuclear keratin reorganization affects the viscoelasticity of metastatic cancer cells and promotes tumor invasion (Beil et al. 2003). Mechanically stretching of keratinocytes expressing EBS-like keratin mutations triggered a progressive disassembly of desmosomes and weakened intercellular adhesion (Russell et al. 2004; Homberg et al. 2015). Thus, keratin reorganization on posttranslational modifications might contribute to the invasive properties of metastatic tumor cells and to altered adhesion in skin disorders (Beil et al. 2003; Russell et al. 2004; Homberg et al. 2015; Loschke et al. 2016).

\section{Intrinsic Keratin Properties and Associated \\ Proteins as Determinants of Network Organization and Stress Resilience}

The organization of cytoskeletal networks depends on their intrinsic properties and their associated proteins, and determines the comprehensive array of functions that they perform (Fletcher and Mullins 2010). Bundling of individual filaments into fibers, an intrinsic keratin property (Lee and Coulombe 2009), is seen in most epithelia, evident in the epidermis and in hair follicles, whereas simple epithelia show less dense arrays. Here, an interesting contributor to IF organization lies in their capacity to form disulfide bonds. With the exception of KRT8, KRT18, and KRT19, all other human and mouse keratins contain variable numbers of cysteine residues. Following the observation that a subset of keratins becomes disulfide-crosslinked on terminal differentiation in vivo, homotypic disulfide bonds involving three Cys residues in KRT14 and one in K10 were identified in cultured keratinocytes and mouse epidermis, in addition to interkeratin disulfide-bonded 
KRT5/14 species (Lee et al. 2012; Feng and Coulombe 2015; Bunick and Milstone, 2016). Available data point to multiple roles of disulfidebonding on keratin assembly, dynamics, and network organization. Intriguingly, disulfide bonding of K14 coincided with formation of networks enriched in the nuclear periphery, a region reactive to mechanical cues (Feng and Coulombe 2015; Wallrath et al. 2016). Disulfide bonding may also alter bending and buckling of keratin networks, which occur on compressive intracellular forces (Nolting et al. 2014). Finally, disulfide bonds in keratins not only alter keratin organization and dynamics on mechanical signals but could tie them to the highly dynamic cellular redox network controlled by the antioxidant transcription factor Nrf2 (Schafer et al. 2012).

In addition to posttranslational modifications, the small heat shock protein Hsp27 and proteins of the plakin and S100 families regulate keratin assembly, bundling, and network organization (Windoffer et al. 2011; Kayser et al. 2013; Bouameur et al. 2014; Lesniak and Graczyk-Jarzynka 2015). Plectin is a plakin protein that links keratin bundling to MAPK signaling. In contrast to prediction, genetic deletion of plectin rendered cells more susceptible to mechanical stress, despite an increase in keratin bundling (Osmanagic-Myers et al. 2006). The latter is consistent with unaltered mechanical properties of plectin knockdown cells as assessed by indentation analyses using AFM and by displacement analyses of cytoplasmic superparamagnetic beads using magnetic tweezers (Moch et al. 2016). To investigate the transmission of forces to the nucleus, which is crucial for nuclear function, a recent study examined plectin's role in controlling nuclear morphology via keratins. On plectin knockdown, actomyosin-dependent nuclear deformation occurred, whereas direct interactions between keratins and the nuclear envelope were not required. Instead, plectin down-regulation reduced KIF density in the nuclear perimeter (Almeida et al. 2015). Possibly, plectin acts as a mechanosensor as it contains a cryptic $\mathrm{SH} 3$ domain in the fifth spectrin repeat of its plakin domain. Following mechanical stress, unfolding of spectrin domains may uncover the hidden $\mathrm{SH} 3$ domain (Osmani and Labouesse 2015).

Very little is known about the interaction of keratins with actin and actomyosin, which is crucial during morphogenesis, cell polarity, cell migration, and invasion. In a study aimed to normalize mutation-disrupted keratin networks in hepatocytes, the multikinase inhibitor PKC412 was found to perform this function by enhancing nonmuscle myosin heavy chain-IIA (NMHC-IIA) interaction with KRT8 and KRT 18 through inhibiting NMHC-IIA phosphorylation (Kwan et al. 2015). Solo (ARHGEF40) is a RhoA-targeting guanine nucleotide exchange factor (GEF) involved in cyclical stretch-induced human endothelial cell reorientation and convergent extension cell movement in zebrafish gastrula and binds to KRT8/18 IF. Knockdown of Solo suppresses tensile force-induced stress fiber reinforcement and RhoA activation. Thus, the interplay between Solo and KRT8/18 plays a crucial role in tensile force-induced RhoA activation and consequent actin cytoskeletal reinforcement (Fujiwara et al. 2016).

\section{CONCLUDING REMARKS}

\section{Desmosomes as Mechanosensors?}

As mentioned above, AJs are considered as the mechanosensing unit in intercellular force transduction and distribution in multicellular tissues. It remains an open question whether or not desmosomes can function as mechanosensors. Although desmosomes are composed of structurally related sets of proteins, including cadherin and armadillo family members, a direct homologue of the key mechanosensor in $\mathrm{AJs}, \alpha$-catenin is lacking. Instead, desmosomes contain the cytoskeletal linker protein DSP with an important role in lateral clustering of cadherins and in linking KIFs to the junction. Its amino-terminal domain interacts with PG/JUP and PKPs, and is essential for DSP clustering and determining desmosome size. This domain contains spectrin repeats homologous to the spectrin repeats found in the related plakin family protein, plectin (Choi and Weis 2011). Spectrin repeat domains undergo only moderate 
M. Hatzfeld et al.

bending under mechanical stress, but repeats were shown to unfold individually at low pulling forces (Rief et al. 1999). Thus, it is possible that the DSP-amino-terminal spectrin repeat domain undergoes force-induced unfolding of individual spectrin repeats leading to conformational changes that might alter DSP-protein interactions. In such a scenario, DSP would act directly as a mechanosensor. Interestingly, several disease-causing mutations cluster in this region and are potentially linked to structural destabilization (Ortega et al. 2016). A central, $\alpha$-helical domain of DSP forms coiled coils leading to homodimerization. In contrast to the spectrin repeat domain, coiled-coils bend easily but are rather resistant to stretching (Adamovic et al. 2008). The carboxy-terminal domain of DSP interacts with keratins and consists of three plakin repeat domains. Whereas the first plakin repeat domains are linked by just four amino acids, plakin repeat domains 2 and 3 are separated by a 154 amino acid linker (Kang et al. 2016). Decoupling of the plakin domains suggests that the hinge region might be extended and strained in an initial step, before the amino-terminal spectrin repeats undergo force-induced conformational changes (Ortega et al. 2016). Therefore, the plakin domain may work as a molecular shock absorber that dissipates elastic energy when cells are subjected to external forces (Ortega et al. 2016).

\section{Desmosomes in Mechanotransduction}

As mentioned before, the Hippo mediators YAP/TAZ may be involved in regulating desmosomes via the transcription factor Tead4 (Liu et al. 2016). Recently, desmosome mutations in AC were linked to modulation of Hippo/YAP signaling, suggesting that there might be a feedback/feedforward mechanism (Chen et al. 2014). In AC, levels of phospho-YAP were increased compared with normal human hearts, and phospho-YAP was recruited to the junctions. In agreement, RNA sequencing, quantitative polymerase chain reaction, and reporter assays all showed suppressed TEAD activity in HL-1 myocytes with a PKP2 knockdown (Chen et al. 2014). We suppose that this mechanism is conserved in epithelial cells and between PKP isoforms because the majority of published YAP targets from mouse keratinocytes (Liu et al. 2016) appeared down-regulated in PKP1 KO keratinocytes (our own unpublished results). Taken together, these data indicate that desmosomes might regulate YAP/TAZ signaling. Because YAP and PG/JUP were coimmunoprecipitated from human heart protein extracts, desmosomes could function along with $\alpha$-catenin to recruit YAP to cell-cell contacts and limit its transcriptional activity.

\section{ACKNOWLEDGMENTS}

Deutsche Forschungsgemeinschaft (DFG) funding to the Hatzfeld and Magin laboratories is gratefully acknowledged (Ha1791/8-1, Ha1791/ 10-1, MA1316-15, MA1316-17, MA1316-19, MA1316-21, INST 268/230-1).

\section{REFERENCES}

${ }^{*}$ Reference is also in this collection.

Acehan D, Petzold C, Gumper I, Sabatini DD, Muller EJ, Cowin P, Stokes DL. 2008. Plakoglobin is required for effective intermediate filament anchorage to desmosomes. J Invest Dermatol 128: 2665-2675.

Adamovic I, Mijailovich SM, Karplus M. 2008. The elastic properties of the structurally characterized myosin II S2 subdomain: A molecular dynamics and normal mode analysis. Biophys J 94: 3779-3789.

Albrecht LV, Zhang L, Shabanowitz J, Purevjav E, Towbin JA, Hunt DF, Green KJ. 2015. GSK3- and PRMT-1-dependent modifications of desmoplakin control desmoplakin-cytoskeleton dynamics. J Cell Biol 208: 597-612.

Al-Jassar C, Bikker H, Overduin M, Chidgey M. 2013. Mechanistic basis of desmosome-targeted diseases. J Mol Biol 425: 4006-4022.

Almeida FV, Walko G, McMillan JR, McGrath JA, Wiche G, Barber AH, Connelly JT. 2015. The cytolinker plectin regulates nuclear mechanotransduction in keratinocytes. J Cell Sci 128: 4475-4486.

Alvarado DM, Coulombe PA. 2014. Directed expression of a chimeric type II keratin partially rescues keratin 5-null mice. J Biol Chem 289: 19435-19447.

Amagai M. 2010. Autoimmune and infectious skin diseases that target desmogleins. Proc Jpn Acad Ser B Phys Biol Sci 86: 524-537.

Amagai M, Stanley JR. 2012. Desmoglein as a target in skin disease and beyond. J Invest Dermatol 132: 776-784.

Bar J, Kumar V, Roth W, Schwarz N, Richter M, Leube RE, Magin TM. 2014. Skin fragility and impaired desmo- 
somal adhesion in mice lacking all keratins. J Invest Dermatol 134: 1012-1022.

Barry ER, Camargo FD. 2013. The Hippo superhighway: Signaling crossroads converging on the Hippo/Yap pathway in stem cells and development. Curr Opin Cell Biol 25: $247-253$.

Beil M, Micoulet A, von Wichert G, Paschke S, Walther P, Omary MB, Van Veldhoven PP, Gern U, Wolff-Hieber E, Eggermann J, et al. 2003. Sphingosylphosphorylcholine regulates keratin network architecture and visco-elastic properties of human cancer cells. Nat Cell Biol 5: $803-$ 811.

Bierkamp C, McLaughlin KJ, Schwarz H, Huber O, Kemler R. 1996. Embryonic heart and skin defects in mice lacking plakoglobin. Dev Biol 180: 780-785.

Bierkamp C, Schwarz H, Huber O, Kemler R. 1999. Desmosomal localization of $\beta$-catenin in the skin of plakoglobin null-mutant mice. Development 126: 371-381.

Bohnekamp J, Cryderman DE, Paululat A, Baccam GC, Wallrath LL, Magin TM. 2015. A Drosophila model of epidermolysis Bullosa Simplex. J Invest Dermatol 135: 2031-2039.

Bologna M, Allen R, Dulbecco R. 1986. Organization of cytokeratin bundles by desmosomes in rat mammary cells. J Cell Biol 102: 560-567.

Bornschlogl T, Bildstein L, Thibaut S, Santoprete R, Fiat F, Luengo GS, Doucet J, Bernard BA, Baghdadli N. 2016. Keratin network modifications lead to the mechanical stiffening of the hair follicle fiber. Proc Natl Acad Sci 113: 5940-5945.

Bornslaeger EA, Godsel LM, Corcoran CM, Park JK, Hatzfeld M, Kowalczyk AP, Green KJ. 2001. Plakophilin interferes with plakoglobin binding to desmoplakin, yet together with plakoglobin promotes clustering of desmosomal plaque complexes at cell-cell borders. J Cell Sci 114: 727-738.

Bouameur JE, Magin TM. 2017. Lessons from animal models of cytoplasmic intermediate filament proteins. In Subcellular biochemistry: Fibrous proteins: Structures and mechanisms (ed. Parry DA, Squire JM), Springer International Publishing, Switzerland (in press).

Bouameur JE, Favre B, Fontao L, Lingasamy P, Begre N, Borradori L. 2014. Interaction of plectin with keratins 5 and 14: Dependence on several plectin domains and keratin quaternary structure. J Invest Dermatol 134: $2776-$ 2783.

Bunick CG, Milstone LM. 2016. The X-ray crystal structure of the keratin 1-keratin 10 helix $2 \mathrm{~B}$ heterodimer reveals molecular surface properties and biochemical insights into human skin disease. J Invest Dermatol. doi: 10.1016/j.jid.2016.08.018.

Calore M, Lorenzon A, De Bortoli M, Poloni G, Rampazzo A. 2015. Arrhythmogenic cardiomyopathy: A disease of intercalated discs. Cell Tissue Res 360: 491-500.

Cerrone M, Delmar M. 2014. Desmosomes and the sodium channel complex: Implications for arrhythmogenic cardiomyopathy and Brugada syndrome. Trends Cardiovasc Med 24: 184-190.

Chan SW, Lim CJ, Chen L, Chong YF, Huang C, Song H, Hong W. 2011. The Hippo pathway in biological control and cancer development. J Cell Physiol 226: 928-939.
Desmosomes and Keratins in Tissue Mechanics

Chen SN, Gurha P, Lombardi R, Ruggiero A, Willerson JT, Marian AJ. 2014. The hippo pathway is activated and is a causal mechanism for adipogenesis in arrhythmogenic cardiomyopathy. Circ Res 114: 454-468.

Cheung KJ, Gabrielson E, Werb Z, Ewald AJ. 2013. Collective invasion in breast cancer requires a conserved basal epithelial program. Cell 155: 1639-1651.

Chidgey M, Brakebusch C, Gustafsson E, Cruchley A, Hail C, Kirk S, Merritt A, North A, Tselepis C, Hewitt J, et al. 2001. Mice lacking desmocollin 1 show epidermal fragility accompanied by barrier defects and abnormal differentiation. J Cell Biol 155: 821-832.

Choi HJ, Weis WI. 2011. Crystal structure of a rigid fourspectrin-repeat fragment of the human desmoplakin plakin domain. J Mol Biol 409: 800-812.

Coulombe PA, Lee CH. 2012. Defining keratin protein function in skin epithelia: Epidermolysis bullosa simplex and its aftermath. J Invest Dermatol 132: 763-775.

Cowin P, Kapprell HP, Franke WW, Tamkun J, Hynes RO. 1986. Plakoglobin: A protein common to different kinds of intercellular adhering junctions. Cell 46: 1063-1073.

Deek J, Hecht F, Rossetti L, Wissmiller K, Bausch AR. 2016. Mechanics of soft epithelial keratin networks depend on modular filament assembly kinetics. Acta Biomater 9: 30326-30329.

Den Z, Cheng X, Merched-Sauvage M, Koch PJ. 2006. Desmocollin 3 is required for pre-implantation development of the mouse embryo. J Cell Sci 119: 482-489.

Dubash AD, Koetsier JL, Amargo EV, Najor NA, Harmon RM, Green KJ. 2013. The GEF Bcr activates RhoA/MAL signaling to promote keratinocyte differentiation via desmoglein-1. J Cell Biol 202: 653-666.

Dupont S, Morsut L, Aragona M, Enzo E, Giulitti S, Cordenonsi M, Zanconato F, Le Digabel J, Forcato M, Bicciato S, et al. 2011. Role of YAP/TAZ in mechanotransduction. Nature 474: 179-183.

Elbediwy A, Vincent-Mistiaen ZI, Spencer-Dene B, Stone RK, Boeing S, Wculek SK, Cordero J, Tan EH, Ridgway R, Brunton VG, et al. 2016. Integrin signalling regulates YAP and TAZ to control skin homeostasis. Development 143: $1674-1687$.

Eshkind L, Tian Q, Schmidt A, Franke WW, Windoffer R, Leube RE. 2002. Loss of desmoglein 2 suggests essential functions for early embryonic development and proliferation of embryonal stem cells. Eur J Cell Biol 81: 592-598.

Evans ND, Oreffo RO, Healy E, Thurner PJ, Man YH. 2013. Epithelial mechanobiology, skin wound healing, and the stem cell niche. J Mech Behav Biomed Mater 28: 397-409.

Feng X, Coulombe PA. 2015. A role for disulfide bonding in keratin intermediate filament organization and dynamics in skin keratinocytes. J Cell Biol 209: 59-72.

Feng X, Zhang H, Margolick JB, Coulombe PA. 2013. Keratin intracellular concentration revisited: Implications for keratin function in surface epithelia. J Invest Dermatol 133: $850-853$.

Fischer H, Langbein L, Reichelt J, Buchberger M, Tschachler E, Eckhart L. 2016. Keratins K2 and K10 are essential for the epidermal integrity of plantar skin. J Dermatol Sci 81: $10-16$.

Fischer H, Langbein L, Reichelt J, Praetzel-Wunder S, Buchberger M, Ghannadan M, Tschachler E, Eckhart L. 2014. 
M. Hatzfeld et al.

Loss of keratin K2 expression causes aberrant aggregation of K10, hyperkeratosis, and inflammation. J Invest Dermatol 134: 2579-2588.

Fletcher DA, Mullins RD. 2010. Cell mechanics and the cytoskeleton. Nature 463: 485-492.

Flitney EW, Kuczmarski ER, Adam SA, Goldman RD. 2009. Insights into the mechanical properties of epithelial cells: The effects of shear stress on the assembly and remodeling of keratin intermediate filaments. FASEB J 23: 2110 2119.

Fois G, Weimer M, Busch T, Felder ET, Oswald F, von Wichert G, Seufferlein T, Dietl P, Felder E. 2013. Effects of keratin phosphorylation on the mechanical properties of keratin filaments in living cells. FASEB J 27: 1322-1329.

Fontao L, Favre B, Riou S, Geerts D, Jaunin F, Saurat JH, Green KJ, Sonnenberg A, Borradori L. 2003. Interaction of the bullous pemphigoid antigen 1 (BP230) and desmoplakin with intermediate filaments is mediated by distinct sequences within their $\mathrm{COOH}$ terminus. $\mathrm{Mol}$ Biol Cell 14: 1978-1992.

Fu DJ, Thomson C, Lunny DP, Dopping-Hepenstal PJ, McGrath JA, Smith FJ, McLean WH, Pedrioli DM. 2014. Keratin 9 is required for the structural integrity and terminal differentiation of the palmoplantar epidermis. J Invest Dermatol 134: 754-763.

Fujiwara S, Ohashi K, Mashiko T, Kondo H, Mizuno K. 2016. Interplay between Solo and keratin filaments is crucial for mechanical force-induced stress fiber reinforcement. Mol Biol Cell 27: 954-966.

Furuse M, Hata M, Furuse K, Yoshida Y, Haratake A, Sugitani Y, Noda T, Kubo A, Tsukita S. 2002. Claudin-based tight junctions are crucial for the mammalian epidermal barrier: A lesson from claudin-1-deficient mice. J Cell Biol 156: 1099-1111.

Gallicano GI, Kouklis P, Bauer C, Yin M, Vasioukhin V, Degenstein L, Fuchs E. 1998. Desmoplakin is required early in development for assembly of desmosomes and cytoskeletal linkage. J Cell Biol 143: 2009-2022.

Garrod D. 2010. Desmosomes in vivo. Dermatol Res Pract 2010: 212439.

Garrod D, Chidgey M. 2008. Desmosome structure, composition and function. Biochim Biophys Acta 1778: 572 587.

Godsel LM, Dubash AD, Bass-Zubek AE, Amargo EV, Klessner JL, Hobbs RP, Chen X, Green KJ. 2010. Plakophilin 2 couples actomyosin remodeling to desmosomal plaque assembly via RhoA. Mol Biol Cell 21: 2844-2859.

Godsel LM, Hsieh SN, Amargo EV, Bass AE, Pascoe-McGillicuddy LT, Huen AC, Thorne ME, Gaudry CA, Park JK, Myung K, et al. 2005. Desmoplakin assembly dynamics in four dimensions: Multiple phases differentially regulated by intermediate filaments and actin. J Cell Biol 171: 1045-1059.

Goldstein J, Horsley V. 2012. Home sweet home: Skin stem cell niches. Cell Mol Life Sci 69: 2573-2582.

Gomez EW, Chen QK, Gjorevski N, Nelson CM. 2010. Tissue geometry patterns epithelial-mesenchymal transition via intercellular mechanotransduction. J Cell Biochem 110: $44-51$.

Gosavi P, Kundu ST, Khapare N, Sehgal L, Karkhanis MS, Dalal SN. 2011. E-cadherin and plakoglobin recruit pla- kophilin3 to the cell border to initiate desmosome assembly. Cell Mol Life Sci 68: 1439-1454.

Green KJ, Gaudry CA. 2000. Are desmosomes more than tethers for intermediate filaments? Nat Rev Mol Cell Biol 1: 208-216.

Green KJ, Getsios S, Troyanovsky S, Godsel LM. 2010. Intercellular junction assembly, dynamics, and homeostasis. Cold Spring Harb Perspect Biol 2: a000125.

Grossmann KS, Grund C, Huelsken J, Behrend M, Erdmann B, Franke WW, Birchmeier W. 2004. Requirement of plakophilin 2 for heart morphogenesis and cardiac junction formation. J Cell Biol 167: 149-160.

Harmon RM, Simpson CL, Johnson JL, Koetsier JL, Dubash AD, Najor NA, Sarig O, Sprecher E, Green KJ. 2013. Desmoglein-1/Erbin interaction suppresses ERK activation to support epidermal differentiation. J Clin Invest 123: $1556-1570$.

Harris AR, Daeden A, Charras GT. 2014. Formation of adherens junctions leads to the emergence of a tissue-level tension in epithelial monolayers. J Cell Sci 127: 25072517.

Harrison OJ, Brasch J, Lasso G, Katsamba PS, Ahlsen G, Honig B, Shapiro L. 2016. Structural basis of adhesive binding by desmocollins and desmogleins. Proc Natl Acad Sci 113: 7160-7165.

Has C, Jakob T, He Y, Kiritsi D, Hausser I, Bruckner-Tuderman L. 2015. Loss of desmoglein 1 associated with palmoplantar keratoderma, dermatitis and multiple allergies. Br J Dermatol 172: 257-261.

Hatzfeld M. 2007. Plakophilins: Multifunctional proteins or just regulators of desmosomal adhesion? Biochim Biophys Acta 1773: 69-77.

Hatzfeld M, Franke WW. 1985. Pair formation and promiscuity of cytokeratins: Formation in vitro of heterotypic complexes and intermediate-sized filaments by homologous and heterologous recombinations of purified polypeptides. J Cell Biol 101: 1826-1841.

Hatzfeld M, Haffner C, Schulze K, Vinzens U. 2000. The function of plakophilin 1 in desmosome assembly and actin filament organization. J Cell Biol 149: 209-222.

Herrmann H, Aebi U. 2016. Intermediate filaments: Structure and assembly. Cold Spring Harb Perspect Biol 8: pii: $\mathrm{a} 018242$.

Herrmann H, Strelkov SV, Burkhard P, Aebi U. 2009. Intermediate filaments: Primary determinants of cell architecture and plasticity. J Clin Invest 119: 1772-1783.

Herrmann H, Wedig T, Porter RM, Lane EB, Aebi U. 2002. Characterization of early assembly intermediates of recombinant human keratins. J Struct Biol 137: 82-96.

Hobbs RP, Green KJ. 2012. Desmoplakin regulates desmosome hyperadhesion. J Invest Dermatol 132: 482-485.

Hobbs RP, Jacob JT, Coulombe PA. 2016. Keratins are going nuclear. Dev Cell 38: 227-233.

Hofmann I, Franke WW. 1997. Heterotypic interactions and filament assembly of type I and type II cytokeratins in vitro: Viscometry and determinations of relative affinities. Eur J Cell Biol 72: 122-132.

Homberg M, Ramms L, Schwarz N, Dreissen G, Leube RE, Merkel R, Hoffmann B, Magin TM. 2015. Distinct impact of two keratin mutations causing epidermolysis bullosa 
simplex on keratinocyte adhesion and stiffness. J Invest Dermatol 135: 2437-2445.

Huveneers S, de Rooij J. 2013. Mechanosensitive systems at the cadherin-F-actin interface. J Cell Sci 126: 403-413.

Jackson BW, Grund C, Schmid E, Burki K, Franke WW, Illmensee K. 1980. Formation of cytoskeletal elements during mouse embryogenesis. Intermediate filaments of the cytokeratin type and desmosomes in preimplantation embryos. Differentiation 17: 161-179.

Janmey PA, Euteneuer U, Traub P, Schliwa M. 1991. Viscoelastic properties of vimentin compared with other filamentous biopolymer networks. J Cell Biol 113: 155-160.

Janmey PA, Wells RG, Assoian RK, McCulloch CA. 2013. From tissue mechanics to transcription factors. Differentiation 86: $112-120$.

Jennings JM, Tucker DK, Kottke MD, Saito M, Delva E, Hanakawa Y, Amagai M, Kowalczyk AP. 2011. Desmosome disassembly in response to pemphigus vulgaris IgG occurs in distinct phases and can be reversed by expression of exogenous Dsg3. J Invest Dermatol 131: 706-718.

Jia J, Li C, Luo S, Liu-Smith F, Yang J, Wang X, Wang N, Lai B, Lei T, Wang Q, et al. 2016. Yes-associated protein contributes to the development of human cutaneous squamous cell carcinoma via activation of RAS. J Invest Dermatol 136: 1267-1277.

Kanai F, Marignani PA, Sarbassova D, Yagi R, Hall RA, Donowitz M, Hisaminato A, Fujiwara T, Ito Y, Cantley LC, et al. 2000. TAZ: A novel transcriptional co-activator regulated by interactions with 14-3-3 and PDZ domain proteins. EMBO J 19: 6778-6791.

Kang H, Weiss TM, Bang I, Weis WI, Choi HJ. 2016. Structure of the intermediate filament-binding region of desmoplakin. PLoS ONE 11: e0147641.

Kanno M, Aoyama Y, Isa Y, Yamamoto Y, Kitajima Y. 2008. P120 catenin is associated with desmogleins when desmosomes are assembled in high- $\mathrm{Ca}^{2+}$ medium but not when disassembled in low-Ca ${ }^{2+}$ medium in DJM-1 cells. J Dermatol 35: 317-324.

Kartenbeck J, Franke WW, Moser JG, Stoffels U. 1983. Specific attachment of desmin filaments to desmosomal plaques in cardiac myocytes. EMBO J 2: 735-742.

Kartenbeck J, Schwechheimer K, Moll R, Franke WW. 1984. Attachment of vimentin filaments to desmosomal plaques in human meningiomal cells and arachnoidal tissue. J Cell Biol 98: 1072-1081.

Kawaguchi M, Kanemaru A, Sawaguchi A, Yamamoto K, Baba T, Lin CY, Johnson MD, Fukushima T, Kataoka H. 2015. Hepatocyte growth factor activator inhibitor type 1 maintains the assembly of keratin into desmosomes in keratinocytes by regulating protease-activated receptor 2dependent p38 signaling. Am J Pathol 185: 1610-1623.

Kayser J, Haslbeck M, Dempfle L, Krause M, Grashoff C, Buchner J, Herrmann H, Bausch AR. 2013. The small heat shock protein Hsp27 affects assembly dynamics and structure of keratin intermediate filament networks. Biophys J 105: 1778-1785.

Keil R, Rietscher K, Hatzfeld M. 2016. Antagonistic regulation of intercellular cohesion by plakophilins 1 and 3 . J Invest Dermatol 29: 32081-32084.
Kimura TE, Merritt AJ, Lock FR, Eckert JJ, Fleming TP, Garrod DR. 2012. Desmosomal adhesiveness is developmentally regulated in the mouse embryo and modulated during trophectoderm migration. Dev Biol 369: $286-$ 297.

Kippenberger S, Bernd A, Loitsch S, Guschel M, Muller J, Bereiter-Hahn J, Kaufmann R. 2000. Signaling of mechanical stretch in human keratinocytes via MAP kinases. J Invest Dermatol 114: 408-412.

Koch PJ, Mahoney MG, Ishikawa H, Pulkkinen L, Uitto J, Shultz L, Murphy GF, Whitaker-Menezes D, Stanley JR. 1997. Targeted disruption of the pemphigus vulgaris antigen (desmoglein 3) gene in mice causes loss of keratinocyte cell adhesion with a phenotype similar to pemphigus vulgaris. J Cell Biol 137: 1091-1102.

Koegel H, von Tobel L, Schafer M, Alberti S, Kremmer E, Mauch C, Hohl D, Wang XJ, Beer HD, Bloch W, et al. 2009. Loss of serum response factor in keratinocytes results in hyperproliferative skin disease in mice. J Clin Invest 119: 899-910.

Koster S, Weitz DA, Goldman RD, Aebi U, Herrmann H. 2015. Intermediate filament mechanics in vitro and in the cell: From coiled coils to filaments, fibers and networks. Curr Opin Cell Biol 32: 82-91.

Kowalczyk AP, Green KJ. 2013. Structure, function, and regulation of desmosomes. Prog Mol Biol Transl Sci 116: 95118.

Kowalczyk AP, Hatzfeld M, Bornslaeger EA, Kopp DS, Borgwardt JE, Corcoran CM, Settler A, Green KJ. 1999. The head domain of plakophilin-1 binds to desmoplakin and enhances its recruitment to desmosomes. Implications for cutaneous disease. J Biol Chem 274: 18145-18148.

Kroger C, Loschke F, Schwarz N, Windoffer R, Leube RE, Magin TM. 2013. Keratins control intercellular adhesion involving PKC- $\alpha$-mediated desmoplakin phosphorylation. J Cell Biol 201: 681-692.

Kuga T, Kume H, Kawasaki N, Sato M, Adachi J, Shiromizu T, Hoshino I, Nishimori T, Matsubara H, Tomonaga T. 2013. A novel mechanism of keratin cytoskeleton organization through casein kinase I $\alpha$ and FAM83H in colorectal cancer. J Cell Sci 126: 4721-4731.

Kuga T, Sasaki M, Mikami T, Miake Y, Adachi J, Shimizu M, Saito Y, Koura M, Takeda Y, Matsuda J, et al. 2016. FAM83H and casein kinase I regulate the organization of the keratin cytoskeleton and formation of desmosomes. Sci Rep 6: 26557.

Kumar V, Behr M, Kiritsi D, Scheffschick A, Grahnert A, Homberg M, Schwieger-Briel A, Jakob T, Bruckner-Tuderman L, Magin TM. 2016. Keratin-dependent thymic stromal lymphopoietin expression suggests a link between skin blistering and atopic disease. J Allergy Clin Immunol 15: 30445-30446.

Kumar V, Bouameur JE, Bar J, Rice RH, Hornig-Do HT, Roop DR, Schwarz N, Brodesser S, Thiering S, Leube $\mathrm{RE}$, et al. 2015. A keratin scaffold regulates epidermal barrier formation, mitochondrial lipid composition, and activity. J Cell Biol 211: 1057-1075.

Kurinna S, Schafer M, Ostano P, Karouzakis E, Chiorino G, Bloch W, Bachmann A, Gay S, Garrod D, Lefort K, et al. 2014. A novel Nrf2-miR-29-desmocollin-2 axis regulates desmosome function in keratinocytes. Nat Commun 5: 5099. 
M. Hatzfeld et al.

Kwan R, Chen L, Looi K, Tao GZ, Weerasinghe SV, Snider NT, Conti MA, Adelstein RS, Xie Q, Omary MB. 2015. PKC412 normalizes mutation-related keratin filament disruption and hepatic injury in mice by promoting keratin-myosin binding. Hepatology 62: 1858-1869.

Ladoux B, Nelson WJ, Yan J, Mege RM. 2015. The mechanotransduction machinery at work at adherens junctions. Integr Biol (Camb) 7: 1109-1119.

Larouche D, Tong X, Fradette J, Coulombe PA, Germain L. 2008. Vibrissa hair bulge houses two populations of skin epithelial stem cells distinct by their keratin profile. $F A$ SEB J 22: 1404-1415.

Lee CH, Coulombe PA. 2009. Self-organization of keratin intermediate filaments into cross-linked networks. J Cell Biol 186: 409-421.

Lee CH, Kim MS, Chung BM, Leahy DJ, Coulombe PA. 2012. Structural basis for heteromeric assembly and perinuclear organization of keratin filaments. Nat Struct Mol Biol 19: 707-715.

Lee MJ, Ran Byun M, Furutani-Seiki M, Hong JH, Jung HS. 2014. YAP and TAZ regulate skin wound healing. J Invest Dermatol 134: 518-525.

Leitner L, Shaposhnikov D, Mengel A, Descot A, Julien S, Hoffmann R, Posern G. 2011. MAL/MRTF-A controls migration of non-invasive cells by upregulation of cytoskeleton-associated proteins. J Cell Sci 124: 4318-4331.

Lesniak W, Graczyk-Jarzynka A. 2015. The S100 proteins in epidermis: Topology and function. Biochim Biophys Acta 1850: $2563-2572$.

Lessard JC, Coulombe PA. 2012. Keratin 16-null mice develop palmoplantar keratoderma, a hallmark feature of pachyonychia congenita and related disorders. J Invest Dermatol 132: 1384-1391.

Li D, Zhang W, Liu Y, Haneline LS, Shou W. 2012. Lack of plakoglobin in epidermis leads to keratoderma. J Biol Chem 287: 10435-10443.

Liu X, Li H, Rajurkar M, Li Q, Cotton JL, Ou J, Zhu LJ, Goel HL, Mercurio AM, Park JS, et al. 2016. Tead and AP1 coordinate transcription and motility. Cell Rep 14: $1169-1180$.

Lloyd C, Yu QC, Cheng J, Turksen K, Degenstein L, Hutton E, Fuchs E. 1995. The basal keratin network of stratified squamous epithelia: Defining K15 function in the absence of K14. J Cell Biol 129: 1329-1344.

Loranger A, Gilbert S, Brouard JS, Magin TM, Marceau N. 2006. Keratin 8 modulation of desmoplakin deposition at desmosomes in hepatocytes. Exp Cell Res 312: $4108-$ 4119.

Loschke F, Homberg M, Magin TM. 2016. Keratin isotypes control desmosome stability and dynamics through PKC $\alpha$. J Invest Dermatol 1: 202-213.

Lowndes M, Rakshit S, Shafraz O, Borghi N, Harmon RM, Green KJ, Sivasankar S, Nelson WJ. 2014. Different roles of cadherins in the assembly and structural integrity of the desmosome complex. J Cell Sci 127: 2339-2350.

Lulevich V, Yang HY, Isseroff RR, Liu GY. 2010. Single cell mechanics of keratinocyte cells. Ultramicroscopy 110: 1435-1442.

Lyle S, Christofidou-Solomidou M, Liu Y, Elder DE, Albelda S, Cotsarelis G. 1998. The C8/144B monoclonal antibody recognizes cytokeratin 15 and defines the location of human hair follicle stem cells. J Cell Sci 111: 3179-3188.

McAleer MA, Pohler E, Smith FJ, Wilson NJ, Cole C, MacGowan S, Koetsier JL, Godsel LM, Harmon RM, Gruber R, et al. 2015. Severe dermatitis, multiple allergies, and metabolic wasting syndrome caused by a novel mutation in the N-terminal plakin domain of desmoplakin. J Allergy Clin Immunol 136: 1268-1276.

McCrea PD, Turck CW, Gumbiner B. 1991. A homolog of the armadillo protein in Drosophila (plakoglobin) associated with E-cadherin. Science 254: 1359-1361.

McGowan KM, Tong X, Colucci-Guyon E, Langa F, Babinet C, Coulombe PA. 2002. Keratin 17 null mice exhibit ageand strain-dependent alopecia. Genes Dev 16: $1412-$ 1422.

McGrath JA. 2005. Inherited disorders of desmosomes. Australas J Dermatol 46: 221-229.

McGrath JA, Mellerio JE. 2010. Ectodermal dysplasia-skin fragility syndrome. Dermatol Clin 28: 125-129.

McGrath JA, McMillan JR, Shemanko CS, Runswick SK, Leigh IM, Lane EB, Garrod DR, Eady RA. 1997. Mutations in the plakophilin 1 gene result in ectodermal dysplasia/skin fragility syndrome. Nat Genet 17: 240-244.

Meens MJ, Pfenniger A, Kwak BR, Delmar M. 2013. Regulation of cardiovascular connexins by mechanical forces and junctions. Cardiovasc Res 99: 304-314.

Meng JJ, Bornslaeger EA, Green KJ, Steinert PM, Ip W. 1997. Two-hybrid analysis reveals fundamental differences in direct interactions between desmoplakin and cell typespecific intermediate filaments. J Biol Chem 272: $21495-$ 21503.

Moch M, Windoffer R, Schwarz N, Pohl R, Omenzetter A, Schnakenberg U, Herb F, Chaisaowong K, Merhof D, Ramms L, et al. 2016. Effects of plectin depletion on keratin network dynamics and organization. PLoS ONE 11: e0149106.

Moll R, Divo M, Langbein L. 2008. The human keratins: Biology and pathology. Histochem Cell Biol 129: 705733.

Muhamed I, Wu J, Sehgal P, Kong X, Tajik A, Wang N, Leckband DE. 2016. E-cadherin-mediated force transduction signals regulate global cell mechanics. J Cell Sci 129: $1843-1854$.

Nolting JF, Mobius W, Koster S. 2014. Mechanics of individual keratin bundles in living cells. Biophys $J$ 107: 2693-2699.

Obarzanek-Fojt M, Favre B, Huber M, Ryser S, Moodycliffe AM, Wipff PJ, Hinz B, Hohl D. 2011. Induction of p38, tumour necrosis factor- $\alpha$ and RANTES by mechanical stretching of keratinocytes expressing mutant keratin 10R156H. Br J Dermatol 164: 125-134.

O’Neill E. 2015. Yap/Taz gets under your skin. Pigment Cell Melanoma Res 28: 243-244.

Ortega E, Manso JA, Buey RM, Carballido AM, Carabias A, Sonnenberg A, de Pereda JM. 2016. The structure of the plakin domain of plectin reveals an extended rod-like shape. J Biol Chem 13: 732909.

Osmanagic-Myers S, Gregor M, Walko G, Burgstaller G, Reipert S, Wiche G. 2006. Plectin-controlled keratin cytoarchitecture affects MAP kinases involved in cellular stress response and migration. J Cell Biol 174: 557-568. 
Osmani N, Labouesse M. 2015. Remodeling of keratin-coupled cell adhesion complexes. Curr Opin Cell Biol 32: 3038.

Pasdar M, Li Z. 1993. Disorganization of microfilaments and intermediate filaments interferes with the assembly and stability of desmosomes in MDCK epithelial cells. Cell Motil Cytoskeleton 26: 163-180.

Patel DM, Green KJ. 2014. Desmosomes in the heart: A review of clinical and mechanistic analyses. Cell Commun Adhes 21: 109-128.

Patel GK, Wilson CH, Harding KG, Finlay AY, Bowden PE. 2006. Numerous keratinocyte subtypes involved in wound re-epithelialization. J Invest Dermatol 126: 497502.

Peters B, Kirfel J, Bussow H, Vidal M, Magin TM. 2001. Complete cytolysis and neonatal lethality in keratin 5 knockout mice reveal its fundamental role in skin integrity and in epidermolysis bullosa simplex. Mol Biol Cell 12: $1775-1789$.

Pigors M, Kiritsi D, Krumpelmann S, Wagner N, He Y, Podda M, Kohlhase J, Hausser I, Bruckner-Tuderman L, Has C. 2011. Lack of plakoglobin leads to lethal congenital epidermolysis bullosa: A novel clinico-genetic entity. Hum Mol Genet 20: 1811-1819.

Pilichou K, Thiene G, Bauce B, Rigato I, Lazzarini E, Migliore F, Perazzolo Marra M, Rizzo S, Zorzi A, Daliento L, et al. 2016. Arrhythmogenic cardiomyopathy. Orphanet J Rare Dis 11: 33.

Ramms L, Fabris G, Windoffer R, Schwarz N, Springer R, Zhou C, Lazar J, Stiefel S, Hersch N, Schnakenberg U, et al. 2013. Keratins as the main component for the mechanical integrity of keratinocytes. Proc Natl Acad Sci 110: $18513-18518$.

Reichelt J, Bussow H, Grund C, Magin TM. 2001. Formation of a normal epidermis supported by increased stability of keratins 5 and 14 in keratin 10 null mice. Mol Biol Cell 12: 1557-1568.

Ridge KM, Linz L, Flitney FW, Kuczmarski ER, Chou YH, Omary MB, Sznajder JI, Goldman RD. 2005. Keratin 8 phosphorylation by protein kinase $\mathrm{C} \delta$ regulates shear stress-mediated disassembly of keratin intermediate filaments in alveolar epithelial cells. J Biol Chem 280: 3040030405.

Rief M, Pascual J, Saraste M, Gaub HE. 1999. Single molecule force spectroscopy of spectrin repeats: Low unfolding forces in helix bundles. J Mol Biol 286: 553-561.

Rietscher K, Wolf A, Hause G, Rother A, Keil R, Magin TM, Glass M, Niessen CM, Hatzfeld M. 2016. Growth retardation, loss of desmosomal adhesion, and impaired tight junction function identify a unique role of plakophilin 1 in vivo. J Invest Dermatol 136: 1471-1478.

Rimpler U. 2014. 'Funktionelle Charakterisierung von Desmocollin 2 während der Embryonalentwicklung und im adulten Herzen in der Maus.' [Functional characterization of desmocollin 2 during embryonic development and in the adult heart in mice.] Dissertation, Humboldt-Universität zu Berlin.

Roth W, Kumar V, Beer HD, Richter M, Wohlenberg C, Reuter U, Thiering S, Staratschek-Jox A, Hofmann A, Kreusch F, et al. 2012. Keratin 1 maintains skin integrity and participates in an inflammatory network in skin through interleukin-18. J Cell Sci 125: 5269-5279.
Ruiz P, Birchmeier W. 1998. The plakoglobin knock-out mouse: A paradigm for the molecular analysis of cardiac cell junction formation. Trends Cardiovasc Med 8: $97-$ 101.

Russell D, Andrews PD, James J, Lane EB. 2004. Mechanical stress induces profound remodelling of keratin filaments and cell junctions in epidermolysis bullosa simplex keratinocytes. J Cell Sci 117: 5233-5243.

Sambandam SA, Kasetti RB, Xue L, Dean DC, Lu Q, Li Q.

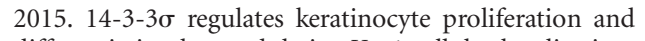
differentiation by modulating Yap1 cellular localization. J Invest Dermatol 135: 1621-1628.

Samuelov L, Sarig O, Harmon RM, Rapaport D, IshidaYamamoto A, Isakov O, Koetsier JL, Gat A, Goldberg I, Bergman R, et al. 2013. Desmoglein 1 deficiency results in severe dermatitis, multiple allergies and metabolic wasting. Nat Genet 45: 1244-1248.

Schafer M, Farwanah H, Willrodt AH, Huebner AJ, Sandhoff K, Roop D, Hohl D, Bloch W, Werner S. 2012. Nrf2 links epidermal barrier function with antioxidant defense. EMBO Mol Med 4: 364-379.

Schlegelmilch K, Mohseni M, Kirak O, Pruszak J, Rodriguez JR, Zhou D, Kreger BT, Vasioukhin V, Avruch J, Brummelkamp TR, et al. 2011. Yap1 acts downstream of $\alpha$ catenin to control epidermal proliferation. Cell 144: $782-795$.

Schwarz N, Windoffer R, Magin TM, Leube RE. 2015. Dissection of keratin network formation, turnover and reorganization in living murine embryos. Sci Rep 5: 9007.

Schweizer J, Bowden PE, Coulombe PA, Langbein L, Lane EB, Magin TM, Maltais L, Omary MB, Parry DA, Rogers MA, et al. 2006. New consensus nomenclature for mammalian keratins. J Cell Biol 174: 169-174.

Seltmann K, Fritsch AW, Kas JA, Magin TM. 2013. Keratins significantly contribute to cell stiffness and impact invasive behavior. Proc Natl Acad Sci 110: 18507-18512.

Sharili AS, Connelly JT. 2014. Nucleocytoplasmic shuttling: A common theme in mechanotransduction. Biochem Soc Trans 42: 645-649.

Shaw TJ, Martin P. 2009. Wound repair at a glance. J Cell Sci 122: 3209-3213.

Simpson CL, Patel DM, Green KJ. 2011. Deconstructing the skin: Cytoarchitectural determinants of epidermal morphogenesis. Nat Rev Mol Cell Biol 12: 565-580.

Sivaramakrishnan S, Schneider JL, Sitikov A, Goldman RD, Ridge KM. 2009. Shear stress induced reorganization of the keratin intermediate filament network requires phosphorylation by protein kinase C $\zeta$. Mol Biol Cell 20: $2755-2765$.

Sklyarova T, Bonne S, D’Hooge P, Denecker G, Goossens S, De Rycke R, Borgonie G, Bosl M, van Roy F, van Hengel J. 2008. Plakophilin-3-deficient mice develop hair coat abnormalities and are prone to cutaneous inflammation. $J$ Invest Dermatol 128: 1375-1385.

Snider NT, Omary MB. 2014. Post-translational modifications of intermediate filament proteins: Mechanisms and functions. Nat Rev Mol Cell Biol 15: 163-177.

Sprecher E, Molho-Pessach V, Ingber A, Sagi E, Indelman M, Bergman R. 2004. Homozygous splice site mutations in PKP1 result in loss of epidermal plakophilin 1 expression and underlie ectodermal dysplasia/skin fragility syn- 
M. Hatzfeld et al.

drome in two consanguineous families. J Invest Dermatol 122: $647-651$.

Stahley SN, Kowalczyk AP. 2015. Desmosomes in acquired disease. Cell Tissue Res 360: 439-456.

Sumigray KD, Lechler T. 2012. Desmoplakin controls microvilli length but not cell adhesion or keratin organization in the intestinal epithelium. Mol Biol Cell 23: $792-$ 799.

Sun TT, Green H. 1978. Keratin filaments of cultured human epidermal cells. Formation of intermolecular disulfide bonds during terminal differentiation. J Biol Chem 253: 2053-2060.

Szeverenyi I, Cassidy AJ, Chung CW, Lee BT, Common JE, Ogg SC, Chen H, Sim SY, Goh WL, Ng KW, et al. 2008. The Human Intermediate Filament Database: Comprehensive information on a gene family involved in many human diseases. Hum Mutat 29: 351-360.

Tariq H, Bella J, Jowitt TA, Holmes DF, Rouhi M, Nie Z, Baldock C, Garrod D, Tabernero L. 2015. Cadherin flexibility provides a key difference between desmosomes and adherens junctions. Proc Natl Acad Sci 112: 5395-5400.

Thomason HA, Cooper NH, Ansell DM, Chiu M, Merrit AJ Hardman MJ, Garrod DR. 2012. Direct evidence that PKC $\alpha$ positively regulates wound re-epithelialization: Correlation with changes in desmosomal adhesiveness. J Pathol 227: 346-356.

Thomason HA, Scothern A, McHarg S, Garrod DR. 2010. Desmosomes: Adhesive strength and signalling in health and disease. Biochem J 429: 419-433.

Todorovic V, Koetsier JL, Godsel LM, Green KJ. 2014. Plakophilin 3 mediates Rap1-dependent desmosome assembly and adherens junction maturation. Mol Biol Cell 25: 3749-3764.

Tucker DK, Stahley SN, Kowalczyk AP. 2014. Plakophilin-1 protects keratinocytes from pemphigus vulgaris IgG by forming calcium-independent desmosomes. J Invest Dermatol 134: 1033-1043.

Tumbar T, Guasch G, Greco V, Blanpain C, Lowry WE, Rendl M, Fuchs E. 2004. Defining the epithelial stem cell niche in skin. Science 303: 359-363.

Vasioukhin V, Bowers E, Bauer C, Degenstein L, Fuchs E. 2001. Desmoplakin is essential in epidermal sheet formation. Nat Cell Biol 3: 1076-1085.

Vijayaraj P, Kroger C, Reuter U, Windoffer R, Leube RE, Magin TM. 2009. Keratins regulate protein biosynthesis through localization of GLUT1 and -3 upstream of AMP kinase and Raptor. J Cell Biol 187: 175-184.

Wallace L, Roberts-Thompson L, Reichelt J. 2012. Deletion of K1/K10 does not impair epidermal stratification but affects desmosomal structure and nuclear integrity. J Cell Sci 125: 1750-1758

Wallis S, Lloyd S, Wise I, Ireland G, Fleming TP, Garrod D. 2000. The $\alpha$ isoform of protein kinase $C$ is involved in signaling the response of desmosomes to wounding in cultured epithelial cells. Mol Biol Cell 11: 1077-1092.
Wallrath LL, Bohnekamp J, Magin TM. 2016. Cross talk between the cytoplasm and nucleus during development and disease. Curr Opin Genet Dev 37: 129-136.

Wan H, Dopping-Hepenstal PJ, Gratian MJ, Stone MG, Zhu G, Purkis PE, South AP, Keane F, Armstrong DK, Buxton RS, et al. 2004. Striate palmoplantar keratoderma arising from desmoplakin and desmoglein 1 mutations is associated with contrasting perturbations of desmosomes and the keratin filament network. Br J Dermatol 150: $878-891$.

Wang J, Zhang Y, Zhang N, Wang C, Herrler T, Li Q. 2015. An updated review of mechanotransduction in skin disorders: Transcriptional regulators, ion channels, and microRNAs. Cell Mol Life Sci 72: 2091-2106.

Watt FM. 1998. Epidermal stem cells: Markers, patterning and the control of stem cell fate. Philos Trans R Soc Lond B Biol Sci 353: 831-837.

Weber GF, Bjerke MA, DeSimone DW. 2012. A mechanoresponsive cadherin-keratin complex directs polarized protrusive behavior and collective cell migration. Dev Cell 22: 104-115.

Windoffer R, Beil M, Magin TM, Leube RE. 2011. Cytoskeleton in motion: The dynamics of keratin intermediate filaments in epithelia. J Cell Biol 194: 669-678.

Yang M, Liang Y, Sheng L, Shen G, Liu K, Gu B, Meng F, Li Q. 2011. A preliminary study of differentially expressed genes in expanded skin and normal skin: Implications for adult skin regeneration. Arch Dermatol Res 303: $125-133$.

Yano S, Komine M, Fujimoto M, Okochi H, Tamaki K. 2004. Mechanical stretching in vitro regulates signal transduction pathways and cellular proliferation in human epidermal keratinocytes. J Invest Dermatol 122: 783-790.

Yao M, Qiu W, Liu R, Efremov AK, Cong P, Seddiki R, Payre M, Lim CT, Ladoux B, Mege RM, et al. 2014. Force-dependent conformational switch of $\alpha$-catenin controls vinculin binding. Nat Commun 5: 4525.

* Yap A. 2017. Mechanosensing and mechanotransduction at cell-cell junctions. Cold Spring Harb Perspect Biol. doi: 10.1101/cshperspect.a028761.

Yates S, Rayner TE. 2002. Transcription factor activation in response to cutaneous injury: Role of AP- 1 in reepithelialization. Wound Repair Regen 10: 5-15.

Yonemura S, Wada Y, Watanabe T, Nagafuchi A, Shibata M. 2010. $\alpha$-Catenin as a tension transducer that induces adherens junction development. Nat Cell Biol 12: 533542.

Yu HH, Dohn MR, Markham NO, Coffey RJ, Reynolds AB. 2016. p120-catenin controls contractility along the vertical axis of epithelial lateral membranes. JCell Sci 129: 8094.

Zhang H, Pasolli HA, Fuchs E. 2011. Yes-associated protein (YAP) transcriptional coactivator functions in balancing growth and differentiation in skin. Proc Natl Acad Sci 108: 2270-2275. 


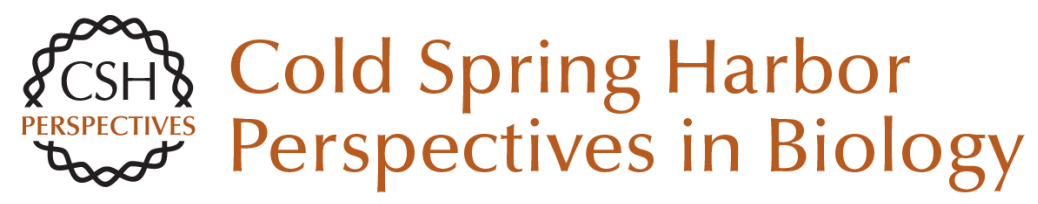

\title{
Desmosomes and Intermediate Filaments: Their Consequences for Tissue Mechanics
}

\author{
Mechthild Hatzfeld, René Keil and Thomas M. Magin
}

Cold Spring Harb Perspect Biol 2017; doi: 10.1101/cshperspect.a029157 originally published online January 17,2017

\section{Subject Collection Cell-Cell Junctions}

Vascular Endothelial (VE)-Cadherin, Endothelial

Adherens Junctions, and Vascular Disease Maria Grazia Lampugnani, Elisabetta Dejana and Costanza Giampietro

Adherens Junctions and Desmosomes

Coordinate Mechanics and Signaling to

Orchestrate Tissue Morphogenesis and Function:

An Evolutionary Perspective

Matthias Rübsam, Joshua A. Broussard, Sara A. Wickström, et al.

\section{Cell-Cell Contact and Receptor Tyrosine Kinase}

Signaling

Christine Chiasson-MacKenzie and Andrea I. McClatchey

Hold Me, but Not Too Tight--Endothelial Cell-Cell Junctions in Angiogenesis

Anna Szymborska and Holger Gerhardt

Connexins and Disease

Mario Delmar, Dale W. Laird, Christian C. Naus, et al.

Cell Junctions in Hippo Signaling

Ruchan Karaman and Georg Halder
Signaling by Small GTPases at Cell-Cell Junctions: Protein Interactions Building Control and Networks

Vania Braga

Making Connections: Guidance Cues and

Receptors at Nonneural Cell-Cell Junctions lan V. Beamish, Lindsay Hinck and Timothy E. Kennedy

The Cadherin Superfamily in Neural Circuit Assembly James $D$. Jontes

Mechanosensing and Mechanotransduction at Cell-Cell Junctions Alpha S. Yap, Kinga Duszyc and Virgile Viasnoff

Beyond Cell-Cell Adhesion: Sensational

Cadherins for Hearing and Balance Avinash Jaiganesh, Yoshie Narui, Raul Araya-Secchi, et al.

Cell-Cell Junctions Organize Structural and Signaling Networks Miguel A. Garcia, W. James Nelson and Natalie Chavez

For additional articles in this collection, see http://cshperspectives.cshlp.org/cgi/collection/

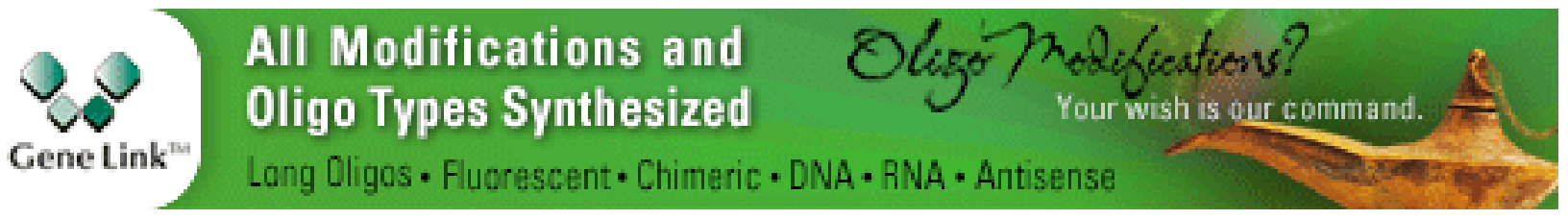


Loss of E-Cadherin-Dependent Cell-Cell Adhesion and the Development and Progression of Cancer Heather C. Bruner and Patrick W.B. Derksen

Desmosomes and Intermediate Filaments: Their Consequences for Tissue Mechanics

Mechthild Hatzfeld, René Keil and Thomas M. Magin
Cell Biology of Tight Junction Barrier Regulation and Mucosal Disease

Aaron Buckley and Jerrold R. Turner

Integration of Cadherin Adhesion and

Cytoskeleton at Adherens Junctions

René Marc Mège and Noboru Ishiyama

For additional articles in this collection, see http://cshperspectives.cshlp.org/cgi/collection/

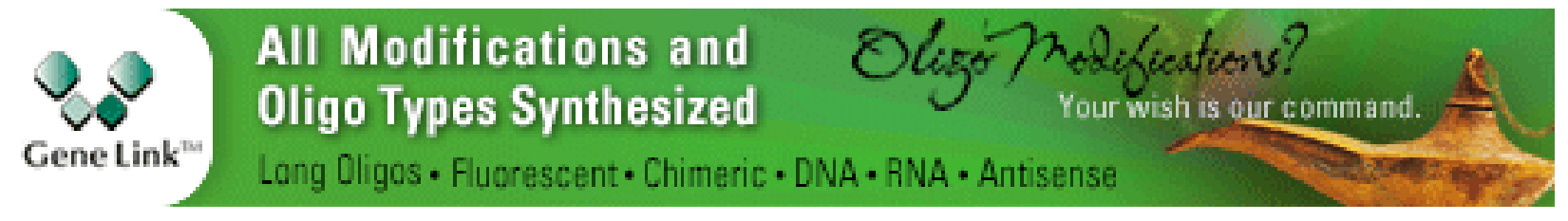

Copyright @ 2017 Cold Spring Harbor Laboratory Press; all rights reserved 